\title{
Coupled Decadal Variability in the North Pacific: An Observationally Constrained Idealized Model*
}

\author{
Bo Qiu, Niklas Schneider, And Shuiming Chen \\ Department of Oceanography, University of Hawaii at Manoa, Honolulu, Hawaii
}

(Manuscript received 15 August 2006, in final form 2 November 2006)

\begin{abstract}
Air-sea coupled variability is investigated in this study by focusing on the observed sea surface temperature signals in the Kuroshio Extension (KE) region of $32^{\circ}-38^{\circ} \mathrm{N}$ and $142^{\circ} \mathrm{E}-180^{\circ}$. In this region, both the oceanic circulation variability and the heat exchange variability across the air-sea interface are the largest in the midlatitude North Pacific. SST variability in the KE region has a dominant time scale of $\sim 10 \mathrm{yr}$ and this decadal variation is caused largely by the regional, wind-induced sea surface height changes that represent the lateral migration and strengthening/weakening of the KE jet. The importance of the air-sea coupling in influencing KE jet is explored by dividing the large-scale wind forcing into those associated with the intrinsic atmospheric variability and those induced by the SST changes in the KE region. The latter signals are extracted from the NCEP-NCAR reanalysis data using the lagged correlation analysis. In the absence of the SST feedback, the intrinsic atmospheric forcing enhances the decadal and longer time-scale SST variance through oceanic advection but fails to capture the observed decadal spectral peak. When the SST feedback is present, a warm (cold) KE SST anomaly works to generate a positive (negative) wind stress curl in the eastern North Pacific basin, resulting in negative (positive) local sea surface height (SSH) anomalies through Ekman divergence (convergence). As these wind-forced SSH anomalies propagate into the KE region in the west, they shift the KE jet and alter the sign of the preexisting SST anomalies. Given the spatial pattern of the SST-induced wind stress curl forcing, the optimal coupling in the midlatitude North Pacific occurs at the period of $\sim 10 \mathrm{yr}$, slightly longer than the basin-crossing time of the baroclinic Rossby waves along the KE latitude.
\end{abstract}

\section{Introduction}

Decadal variability in the midlatitude North Pacific has received considerable attention in recent years because of its impact upon the Pacific marine ecosystems and long-term weather fluctuations over the North America continent. Comprehensive reviews on the North Pacific decadal variability can be found in recent articles by Pierce et al. (2001), Mantua and Hare (2002), Miller et al. (2004), and the references listed therein. Analyses of the sea surface temperature (SST) data have revealed that the low-frequency SST changes in the North Pacific consist of two dominant modes: one

* IPRC Contribution Number 437.

Corresponding author address: Dr. Bo Qiu, Department of Oceanography, University of Hawaii at Manoa, 1000 Pope Road, Honolulu, HI 96822.

E-mail: bo@soest.hawaii.edu that is remotely forced by teleconnected ENSO signals and the other that is associated with the processes intrinsic to the midlatitude North Pacific (e.g., Deser and Blackmon 1995; Nakamura et al. 1997; Zhang et al. 1997). The former mode, also known as the ENSO mode, has a center of action in the central, eastern North Pacific, whereas the latter mode (the North Pacific mode) has its center of action confined to the western half of the midlatitude North Pacific basin. Compared to the ENSO mode, the North Pacific mode has been observed to have more power in the SST spectrum on the decadal-to-multidecadal time scales. It is on the North Pacific mode that the present study will focus.

Decadal-to-multidecadal time-scale SST variability in a midlatitude ocean can be generated through three different scenarios. The first is the climate noise scenario (aka the null hypothesis) in which the lowfrequency SST variability simply reflects low-frequency changes in the short time-scale statistics of the atmospheric forcing (Hasselmann 1976; Frankignoul and Hasselmann 1977). The second scenario emphasizes the

DOI: 10.1175/JCLI4190.1 
ocean circulation and its slow response in contributing to the reddening of the SST signals. While the ocean dynamics is active in this scenario, it is assumed to have no dynamically important impact upon the overlying atmosphere through the resulting SST changes. Under this "uncoupled" scenario, several mechanisms have been proposed that can give rise to preferred time scales in SST, including advection of the mean upperocean circulation (Saravanan and McWilliams 1998), spatial pattern of the atmospheric forcing (Jin 1997; Frankignoul et al. 1997; Weng and Neelin 1998; Saravanan and McWilliams 1998; Neelin and Weng 1999), latitude-dependent Rossby wave adjustment (Qiu 2003; Schneider and Cornuelle 2005), and inertial recirculation gyre dynamics (e.g., Dewar 2001; Hogg et al. 2005; Taguchi et al. 2005; Pierini 2006).

The third scenario regards the midlatitude ocean and atmosphere as a coupled system in which the strength and frequency of the low-frequency variability are determined by both the ocean dynamics and its feedback to the atmospheric circulation (Bjerknes 1964). Latif and Barnett $(1994,1996)$ explored this scenario and identified a 20-yr coupled mode in the midlatitude North Pacific by using a coupled general circulation model (CGCM). The existence of the coupled modes in the North Pacific have also been examined by Pierce et al. (2001), Schneider et al. (2002), Wu et al. (2003), and Kwon and Deser (2007), using various long-term CGCM runs. While the ocean-to-atmosphere feedback processes vary subtly from model to model, all CGCM studies point to the importance of the Kuroshio Extension (KE) variability in controlling the regional SST signals and to the role played by the baroclinic Rossby waves in the KE's response to the time-varying surface wind stress forcing (see also Miller et al. 1998; Deser et al. 1999; Xie et al. 2000; Seager et al. 2001).

It is worth emphasizing that clarifying the nature and the mechanism of the decadal-to-multidecadal SST variability is important from the prediction perspective (Pierce et al. 2001). While the climate noise scenario would suggest very limited predictive skill, the deterministic ocean dynamics in scenario 2 can potentially improve the predictive skill significantly (Schneider and Miller 2001; Scott 2003; Scott and Qiu 2003). In the coupled scenario, predictability may be further enhanced by taking into account the feedback part of the atmospheric forcing. In the past, an effective method of distinguishing the three scenarios listed above has been through numerical modeling in which one tests various hypotheses by altering the complexity of the ocean dynamics or by conducting partial coupling experiments (e.g., Barnett et al. 1999; Pierce et al. 2001; Schneider et al. 2002; Dommengnet and Latif 2002; Wu et al. 2003;
Solomon et al. 2003). In the present study, we attempt to explore the relevance of the above three scenarios by analysis of available observational data and adoption of idealized models with different dynamic complexities.

We begin the study by describing the SST, sea surface height, and surface wind stress data in section 2 . With our interest in the coupling between the midlatitude ocean and atmosphere, we introduce in section 3 an SST index taken along the KE band centered along $35^{\circ} \mathrm{N}$. This section provides the rationale for selecting this band and discusses the result under the climate noise scenario. In section 4, we explore the uncoupled scenario by looking into how surface wind variability affects the SSH changes in the KE band, and to what extent the changing SSH signals, in turn, modify the regional SST anomalies. The influence of the SST changes in the KE band upon the basin-scale surface wind stress field is examined in section 5. Section 6 explores the differences between the coupled and uncoupled scenarios, and the results are used to better understand the KE SST anomalies. Discussions and summary of the present study are provided in section 7 .

\section{Data}

Several observational datasets are used in this study to construct an idealized midlatitude air-sea coupled model and to explore underlying causes for the observed decadal signals in the SST field of the North Pacific Ocean. For the SST data, we utilize the Extended Reconstruction SST version 2 (ERSST.v2) product compiled by Smith and Reynolds (2004). The monthly ERSST.v2 dataset has a $2^{\circ}$ spatial resolution and covers the period from 1948 to 2005 .

Monthly surface wind stress and net heat flux data from the National Centers for Environmental Prediction-National Center for Atmospheric Research (NCEP-NCAR) reanalysis (Kistler et al. 2001) are used in this study to represent the atmospheric forcing field. The reanalysis dataset has a spatial resolution of $1.9^{\circ}$ latitude $\times 1.875^{\circ}$ longitude and covers the same 1948-2005 period as the SST dataset. For both the atmospheric and SST data, we derive their monthly anomalies by removing their respective climatological monthly values.

With the advent of satellite altimetry measurements of sea surface height (SSH), our ability to monitor the global surface ocean circulation has improved significantly after 1992. The satellite altimetry data are used in this study to capture the large-scale signals of the time-varying surface ocean circulation. We use the global SSH anomaly dataset compiled by the Collecte, Localisation, Satellites (CLS) Space Oceanographic Division of Toulouse, France. The dataset merges the 


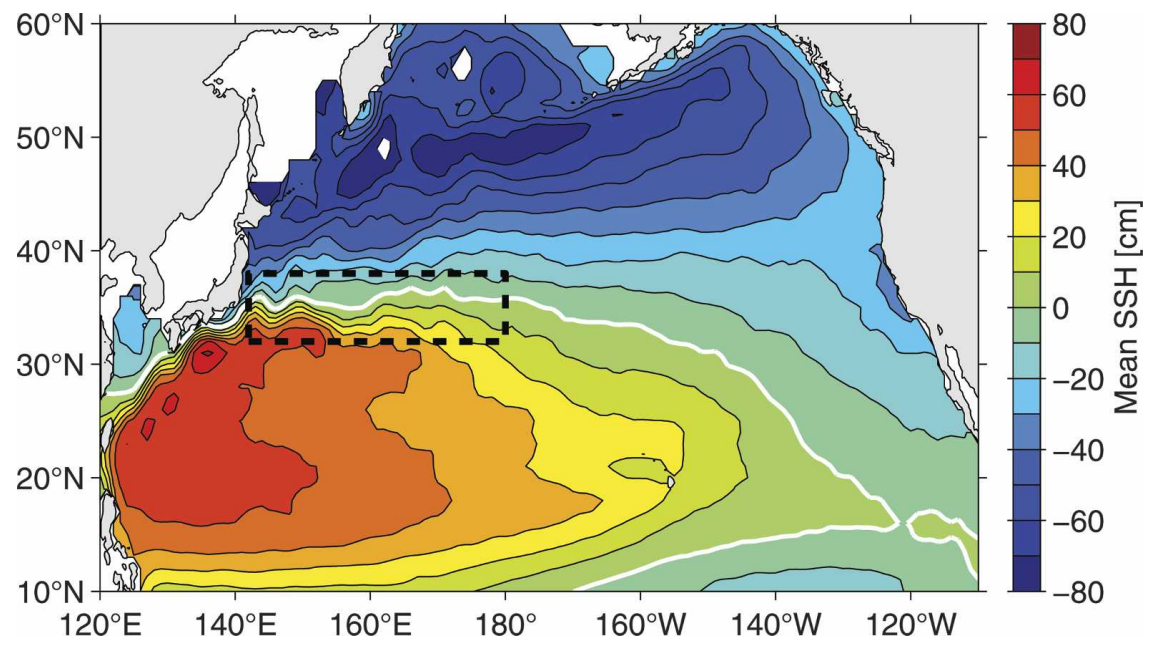

FIG. 1. Mean SSH topography of the North Pacific (adapted from Niiler et al. 2003). Contour intervals (CIs) are $10 \mathrm{~cm}$. Dashed line indicates the Kuroshio Extension band of $142^{\circ} \mathrm{E}-180^{\circ}$ and $32^{\circ}-38^{\circ} \mathrm{N}$.

Ocean Topography Experiment (TOPEX)/Poseidon, Jason-1, and European Remote Sensing Satellite (ERS)1/-2 along-track SSH measurements and has the improved capability of detecting mesoscale SSH signals (Le Traon and Dibarboure 1999; Ducet et al. 2000). The CLS SSH anomaly dataset has a 7-day temporal resolution, a $1 / 3^{\circ} \times 1 / 3^{\circ}$ Mercator spatial resolution, and covers the period from October 1992 to December 2005.

\section{The KE SST index}

As the interest of our investigation is in the air-sea coupled mode in the midlatitude North Pacific, we will focus on a band centered along $35^{\circ} \mathrm{N}$ in the western North Pacific. As shown in Fig. 1 (dashed line), the band has a width of $6^{\circ}$ latitude $\left(32^{\circ}-38^{\circ} \mathrm{N}\right)$ and extends from $142^{\circ} \mathrm{E}$ to the date line. Because it encompasses the eastward-flowing $\mathrm{KE}$ jet, the band will be referred to hereafter as the KE band. Notice that many of the previous studies of the Pacific decadal variability have focused on the subarctic front band centered along $40^{\circ} \mathrm{N}$ (e.g., Miller et al. 1994; Deser and Blackmon 1995; Nakamura et al. 1997; Pierce et al. 2001; Wu et al. 2003; Kwon and Deser 2007). The selection was commonly based on EOF analysis of the wintertime SST signals. Because the SST gradient is greater across the subarctic front than across the KE front, the variance-based analysis of EOF tends to emphasize the variability of the subarctic front (Nakamura and Kazmin 2003; Nonaka et al. 2006).

There are two reasons for our study to choose the southerly KE band. From the atmospheric point of view, if the oceanic variability is to influence the overlying atmosphere, it would be through the anomalous air-sea surface heat flux forcing. A look at the anomalous wintertime surface heat flux data from the NCEPNCAR reanalysis reveals that its largest variations over the open North Pacific Ocean follow the path of the KE jet from the coast of Japan to the date line (see Fig. 2a).

Oceanographically, the KE band is where the surface geostrophic circulation has the largest variance on interannual-to-decadal time scales. To corroborate this point, we plot in Fig. $2 \mathrm{~b}$ the rms amplitude of the SSH anomalies from the satellite altimeter measurements that are low-pass filtered to retain signals longer than 18 months. From the map, it is obvious that the lowfrequency changes in the oceanic circulation are concentrated along the KE band of our interest. This second point is important because we are interested in the mode in which the ocean circulation changes are expected to play an active role.

Figure 3 a shows the time series of the monthly SST anomalies in the KE band from 1948 to 2005. A visual inspection of the time series reveals that in addition to the existence of a very low frequency, warm-coldwarm signal over the 58-yr record, warm SST anomalies dominated in years around 1951, 1956, 1961-62, 196972, 1978-82, 1989-91, and 1999-2001. The dominance of this quasi-decadal signal is confirmed by the power spectrum of the time series shown in Fig. 3b.

Given the SST time series presented in Fig. 3a, it is helpful to start by exploring the "climate noise hypothesis" of Hasselmann (1976) and Frankignoul and Hasselmann (1977). Under this hypothesis, the red spectrum of SST (Fig. 3b) simply reflects year-to-year or 
(a) RMS amplitude of JFM net heat flux

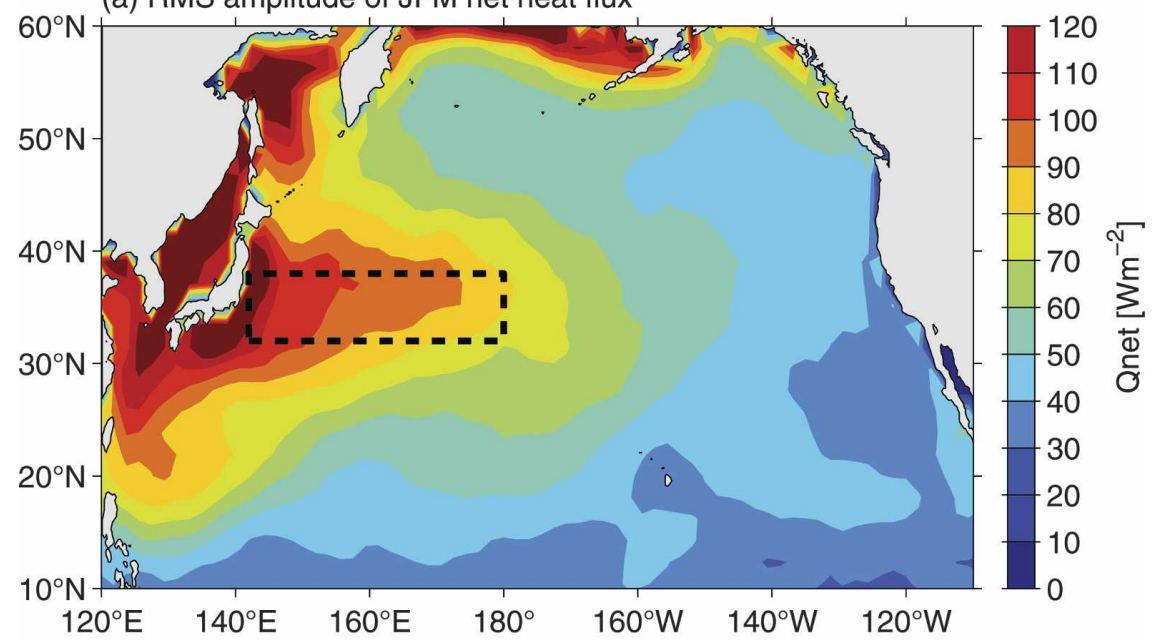

(b) RMS amplitude of SSH variability (10/92-12/05)

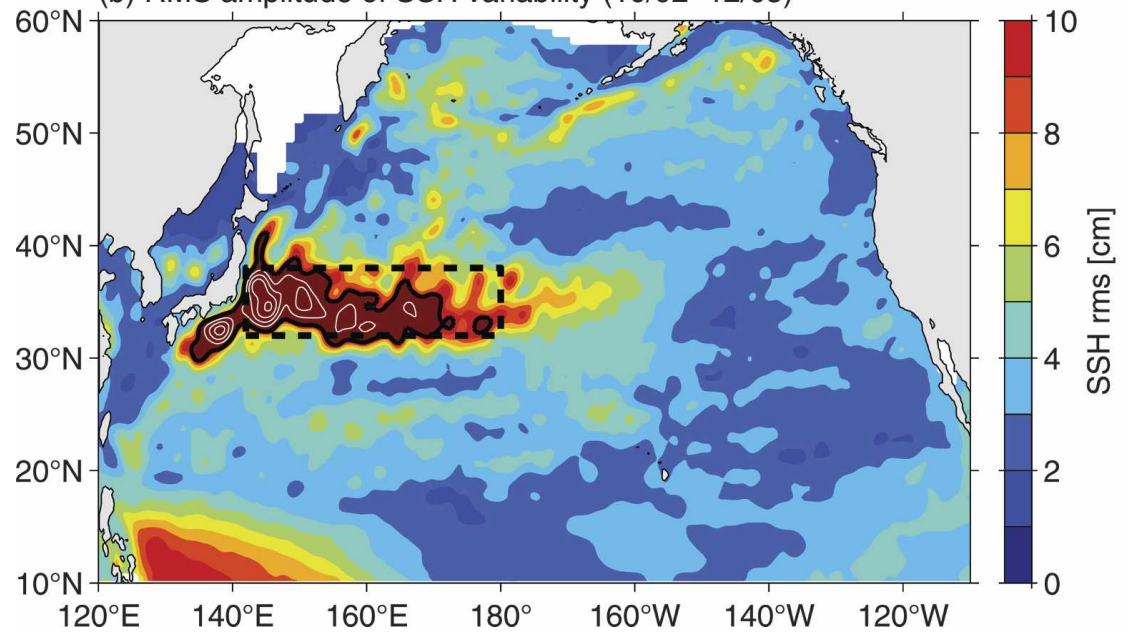

FIG. 2. Root-mean-squared (rms) amplitudes of (a) the wintertime (JFM) net surface heat flux anomalies and (b) the low-passed filtered (with a 2-yr cutoff) SSH variability in the North Pacific, based on the NCEP-NCAR reanalysis of 1948-2005 for (a) and the satellite altimetric data of October 1992-December 2005 for (b). In both panels the dashed line indicates the Kuroshio Extension band of $142^{\circ} \mathrm{E}-180^{\circ}$ and $32^{\circ}-38^{\circ} \mathrm{N}$.

decade-to-decade changes in the white noise atmospheric forcing:

$$
\frac{\partial T}{\partial t}=-\lambda T+q(t),
$$

where $\lambda$ denotes the thermal damping rate and $q(t)$ denotes the white noise atmospheric forcing. By least squares fitting the observed SST time series of Fig. 3a to Eq. (1), we find $\lambda^{-1}=138$ days ( $\sim 4.5$ months $)$ and that the variance for $q(t)$ is equal to $1.83 \times 10^{-14} \mathrm{~K}^{2} \mathrm{~s}^{-2}$. The red curve in Fig. $3 \mathrm{~b}$ shows the SST spectrum based on the climate noise model with the above best-fit $\lambda$ and $q$ values. There is an overall agreement in spectral shape between the two SST spectra, indicating the usefulness of Eq. (1) in understanding the SST signals in midlatitude oceans. In the intra-annual frequency band $(\omega>1$ cpy), the observed SST variance appears to exceed consistently the fitting based on the simple noise model. This discrepancy is likely due to the deficiency of Eq. (1) in capturing the seasonal reemergence process (see Dommengnet and Latif 2002; Deser et al. 2003; Schneider and Cornuelle 2005). The largest difference in spectral level occurs near $\omega=0.1$ cpy in Fig. 3b where the climate noise model fails to capture the observed decadal spectral peak.

A widely used index for the long-term climate vari- 

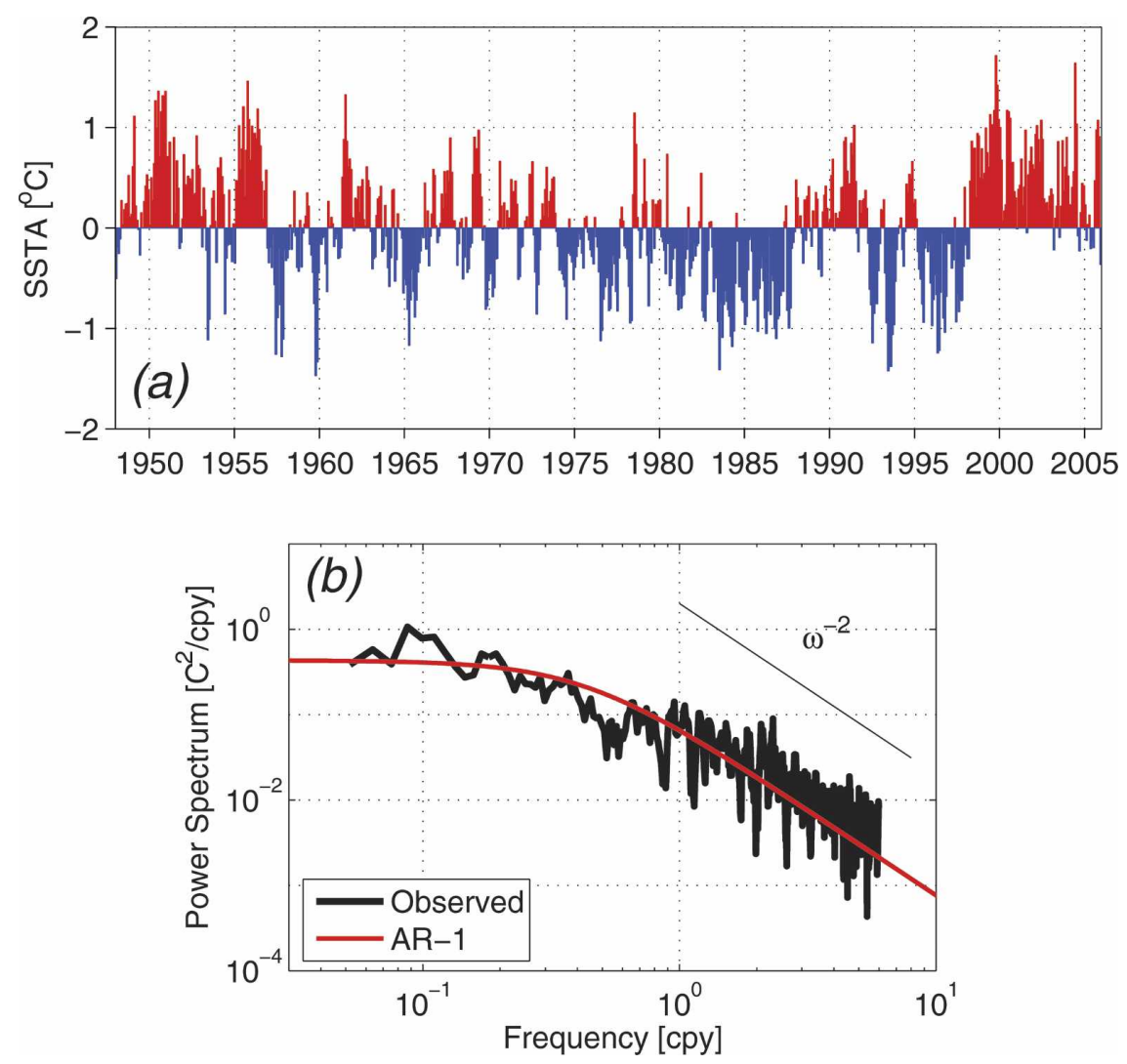

FIG. 3. (a) Time series of the monthly SST anomalies averaged in the KE band. (b) Power spectrum of the SST anomaly time series. Red line indicates the best fit based on a first-order autoregressive process, climate noise model.

ability in the North Pacific is the "Pacific decadal oscillation (PDO)" index defined as the leading component of the North Pacific monthly SST anomalies north of $20^{\circ} \mathrm{N}$ (Mantua et al. 1997; see Fig. 4a). While the KE SST index given in Fig. 3a shares some similarities with the PDO index (the two time series are linearly correlated at -0.63), the PDO index lacks the decadal spectral peak detected in the KE SST index. In fact, the climate noise model provides a better explanation for the PDO time series than it does for the KE SST time series (Fig. 4b; see also Pierce 2001). It is worth emphasizing that the PDO-related SST anomalies have their center of action located along $40^{\circ} \mathrm{N}$, where the oceanic circulation variability is less active than along the $\mathrm{KE}$ band (recall Fig. 2b). In the following sections, we examine how inclusion of the oceanic variability modifies the SST spectrum in the KE band on the decadal and longer time scales.

\section{Climate noise model for SST with the advective effect}

To understand how oceanic circulation variability can change the SST signals in the KE band, we explore two dynamic processes in this section: 1) the upper ocean's adjustment to the time-varying atmospheric forcing, and (2) the SSTs change in the KE band resulting from the changing SSH field.

\section{a. Oceanic adjustment to the changing wind stress field}

It is well established that the large-scale SSH (or, equivalently, the upper-ocean thermocline) variability is controlled by baroclinic Rossby wave dynamics. Specifically, the linear vorticity equation under the longwave approximation states

$$
\frac{\partial h}{\partial t}-c_{R} \frac{\partial h}{\partial x}=-\frac{g^{\prime} \operatorname{curl} \tau}{\rho_{o} g f},
$$

where $h$ is the SSH anomaly, $c_{R}$ is the speed of the long baroclinic Rossby waves, $g$ is the gravitational constant, $g^{\prime}$ is the reduced gravity, $\rho_{o}$ is the reference density, $f$ is the Coriolis parameter, and $\tau$ is the anomalous wind stress vector. Given the wind stress curl data, Eq. (2) can be easily solved by integration along the baroclinic Rossby wave characteristic: 

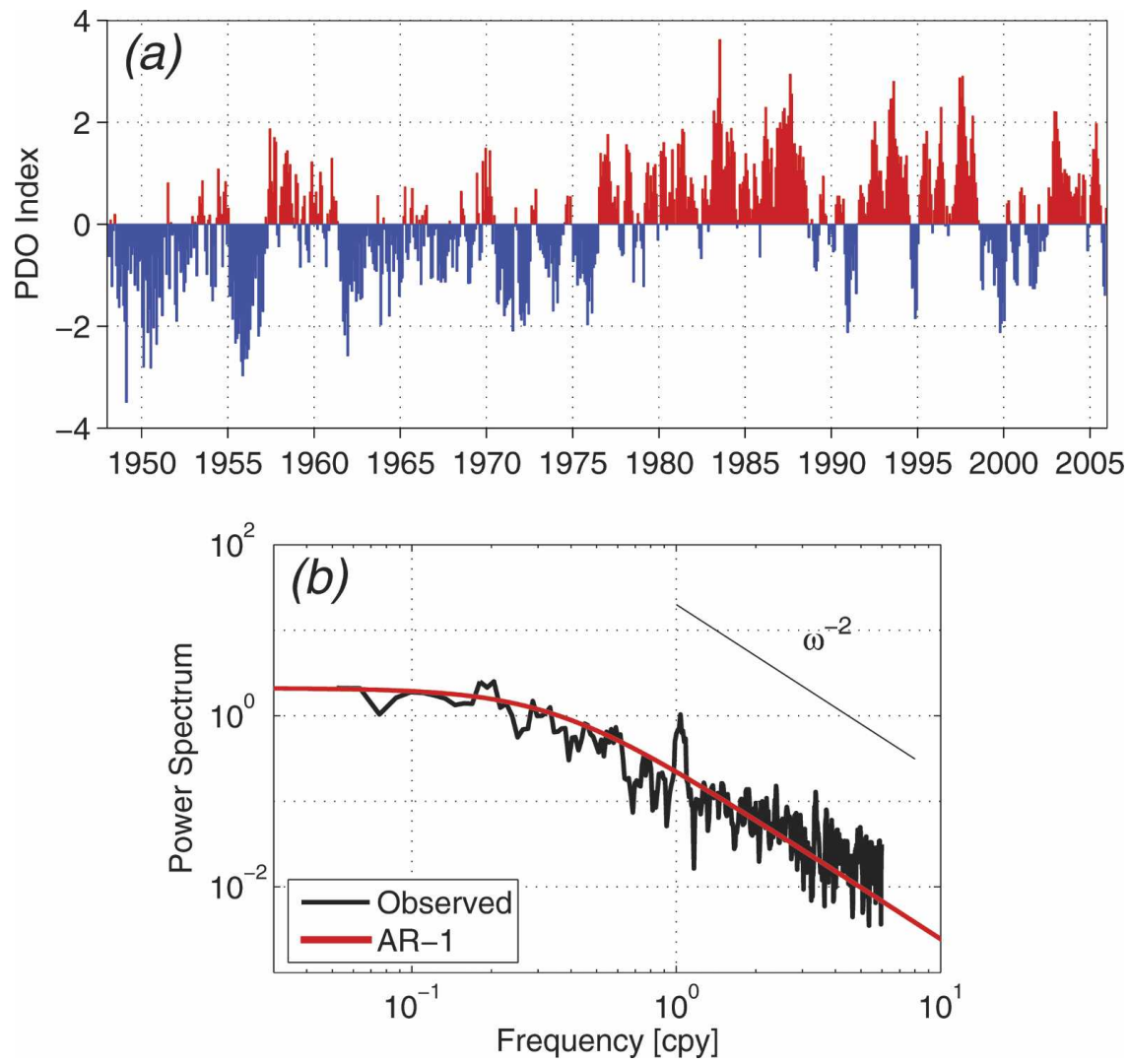

FIG. 4. Same as in Fig. 3 except for the monthly PDO index (available online at http:// jisao.washington.edu/pdo/PDO.latest).

$$
h(x, t)=\frac{g^{\prime}}{c_{R} \rho_{o} g f} \int_{0}^{x} \operatorname{curl} \tau\left(x^{\prime}, t+\frac{x-x^{\prime}}{c_{R}}\right) d x^{\prime} .
$$

In Eq. (3), we have ignored the solution due to the eastern boundary forcing at $x=0$. As detailed in $\mathrm{Fu}$ and Qiu (2002), contributions from the eastern boundary forcing in the midlatitude North Pacific is largely confined to the area a few Rossby radii away from the boundary.

The importance of the Rossby wave dynamics in hindcasting the SSH changes has been pointed out in several OGCM and CGCM studies focusing on the KE variability (e.g., Xie et al. 2000; Seager et al. 2001; Schneider et al. 2002). Indeed, the relevance of Eq. (2) is favorably supported by observations. Figure 5a shows the time-longitude plot of the SSH anomalies along $32^{\circ}-34^{\circ} \mathrm{N}$ across the North Pacific Ocean from the satellite altimeter measurements. Using the monthly wind stress curl data from the NCEP-NCAR reanalysis, we plot in Fig. 5b the $h(x, t)$ field in the same latitudinal band based on Eq. (3). Although the observed SSH field in the KE region contains mesoscale eddy signals that are missing in Fig. 5b, the large-scale decadal SSH changes (e.g., positive SSH anomalies in 1992-95 and 2001-04 and negative SSH anomalies in 1996-2000 and 2005 in the $\mathrm{KE}$ region west of $160^{\circ} \mathrm{E}$ ) are captured well by Eq. (2). The linear correlation coefficient between the observed and modeled $h(x, t)$ fields is $r=0.54$, and this coefficient increases to 0.62 when only the interannual SSH signals are retained in Fig. 5a.

The dominance of the long baroclinic Rossby wave dynamics in determining the SSH changes in the $\mathrm{KE}$ region points to the importance of the wind stress curl forcing in the KE's latitudinal band. With the wind stress curl variability being weak at the ocean's eastern and western boundaries, this forcing field [i.e., the rhs of Eq. (2)] can be mathematically decomposed using the basis function of sine:

$$
-\frac{g^{\prime} \operatorname{curl} \tau(x, t)}{\rho_{o} g f}=\sum_{n=1}^{N} \sin \left(\frac{n \pi x}{W}\right) w_{n}(t),
$$

where $x=-W$ denotes the western boundary of the basin, $w_{n}(t)$ is the temporal coefficient for the $n$th spatial mode, and $N$ is the highest spatial mode resolved by 
(a) Altimetry SSH anomaly

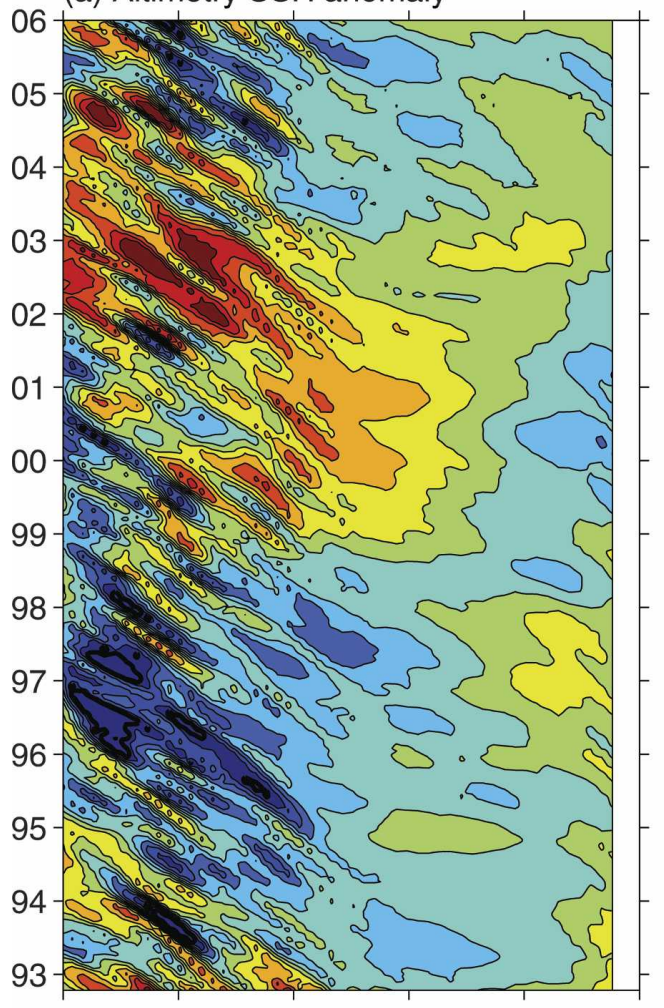

(b) Model SSH anomaly

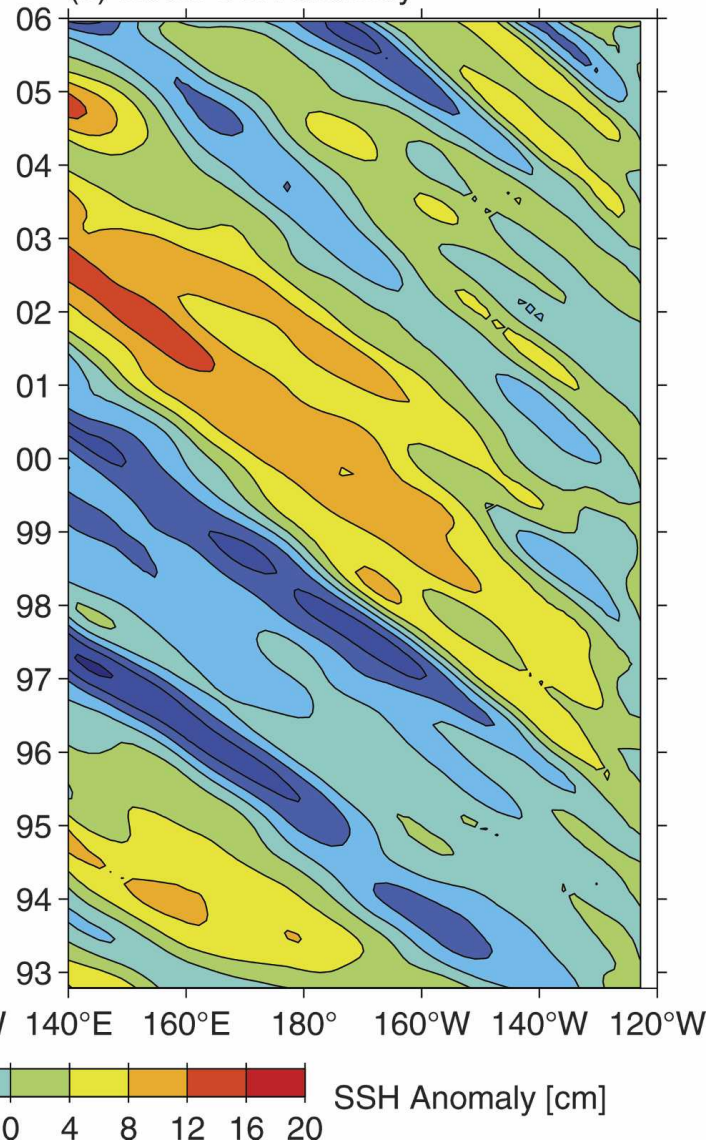

FIG. 5. SSH anomalies along the zonal band of $32^{\circ}-34^{\circ} \mathrm{N}$ from (a) the satellite altimeter data and (b) the wind-forced baroclinic Rossby wave model; see Eq. (2).

the NCEP-NCAR reanalysis data. Notice that while a large number of modes is needed to represent the wind stress curl variability, a significantly smaller number of modes is required to simulate the time-varying $\mathrm{SSH}$ signals in the KE band.

To quantify this point, we form the monthly $\operatorname{curl} \tau(x, t)$ field averaged between $32^{\circ}$ and $38^{\circ} \mathrm{N}$. The dashed line in Fig. 6a shows the percentage of the cumulative variance over the total wind stress curl variance when the number of spatial modes in Eq. (4) is increased. To capture $90 \%$ of the total variance, the 10 lowest spatial modes are required. The wind stress curl field defined in Eq. (4) can be used to calculate the SSH signals averaged in the KE band [recall Eq. (3)]:

$$
\overline{h_{s}}(t) \equiv \frac{1}{L} \int_{-W}^{-W+L}\left[-\frac{1}{c_{R}} \int_{0}^{x} \sum_{n=1}^{s} \sin \left(\frac{n \pi x^{\prime}}{W}\right) w_{n}\left(t+\frac{x-x^{\prime}}{c_{R}}\right) d x^{\prime}\right] d x
$$

where $L$ is the zonal length of the KE band and $\overline{h_{s}}$ denotes the SSH signals induced by the wind forcing with spatial modes $\leq s$. (Thus defined, $\overline{h_{N}}$ gives the $\mathrm{SSH}$ signals induced by the full wind forcing.) In Fig. 6a, we plot in solid line the ratio of the variance for $\overline{h_{s}}$ over that for $\overline{h_{N}}$. In contrast to the wind variance (the dashed line), only the two lowest modes of the wind forcing are needed to capture $90 \%$ of the total SSH variance [see Fig. $6 \mathrm{~b}$ for comparison between the time series $\overline{h_{N}}(t)$ and $\left.\overline{h_{2}}(t)\right]$. Physically, wind forcing with high spatial modes is unimportant for $\bar{h}(t)$ because the integration along the Rossby wave characteristic in Eq. (5) works as an effective spatial filter. In addition, we are interested in the SSH signals averaged in the KE band, 

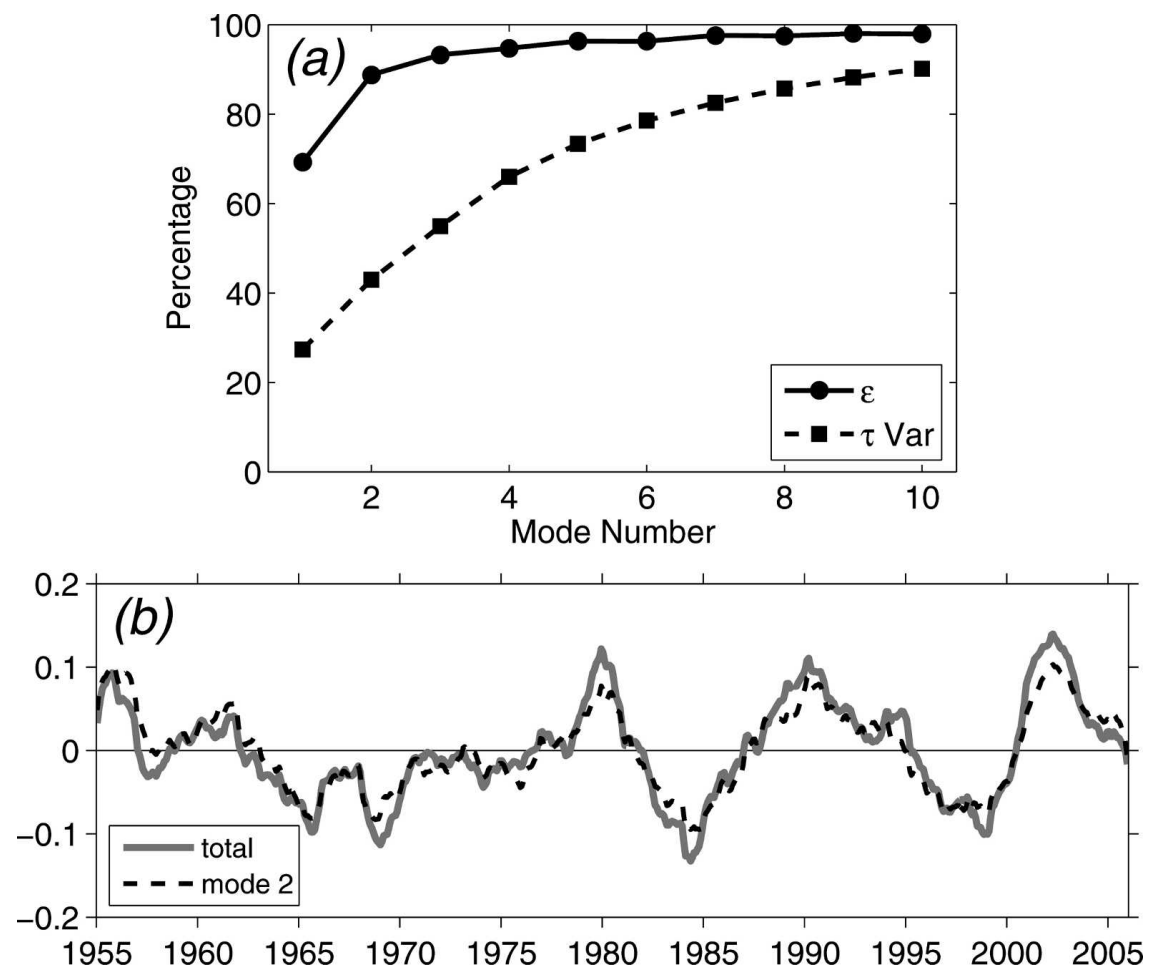

FIG. 6. (a) Dashed line shows the percentage of the cumulative variance over the total wind stress curl variance as a function of spatial modes $s$ defined in Eq. (4). Solid line shows the ratio of the SSH variance explained by the Rossby wave model driven by the wind forcing with spatial modes lower than $s$. (b) SSH time series in the KE band driven by the full wind forcing (solid line) vs the wind forcing with the two lowest spatial modes (dashed line).

which further filters out the small-scale wind forcing effect.

Given the importance of the two lowest modes of wind forcing, we plot in Figs. $7 \mathrm{a}$ and $7 \mathrm{~b}$ the time series of $w_{1}(t)$ and $w_{2}(t)$, respectively. Unlike the SST signals shown in Fig. 3, both modes have a largely "white" spectrum and this is particularly true for $w_{1}(t)$. These white spectra reflect the dominance of the intrinsic atmospheric variability in the midlatitude North Pacific. Averaged over the frequency band, the magnitudes of spectral power for $w_{1}(t)$ and $w_{2}(t)$ are $\left|\hat{w}_{1}(\omega)\right|^{2}=1.127 \times$ $10^{-18}\left(\mathrm{~m} \mathrm{~s}^{-1}\right)^{2} \mathrm{cpy}^{-1}$ and $\left|\hat{w}_{2}(\omega)\right|^{2}=6.429 \times 10^{-19}$ $\left(\mathrm{m} \mathrm{s}^{-1}\right)^{2} \mathrm{cpy}^{-1}$, respectively.

\section{b. SSH-induced SST changes in the KE band}

As the wind-induced positive (negative) SSH anomalies propagate from the central North Pacific, previous studies based on the satellite altimetry data analysis indicate that they tend to enhance (weaken) the zonal $\mathrm{KE}$ jet and shift the path of the KE jet northward (southward) (Qiu 2000; Vivier et al. 2002; Kelly 2004; Qiu and Chen 2005). Both of these processes work to increase (decrease) the SST value in the KE band. To include the time-varying SSH effect on the SST signals in the KE band, we extend the climate noise model, Eq. (1), to

$$
\frac{\partial T(t)}{\partial t}=a \overline{h_{N}}(t)-\lambda T(t)+q(t)
$$

where $\overline{h_{N}}(t)$ is defined in Eq. (5) and $a$ is a coefficient relating the SSH changes to those of SST in the KE band. In their respective analyses of coupled model outputs, Schneider et al. (2002) and Kwon and Deser (2007) have found that the low-frequency SSH signals in the model's KE band represented well the heat convergence associated with the geostrophic surface ocean circulation. In other words, the $a \overline{h_{N}}(t)$ term in Eq. (6) can be interpreted physically as representing geostrophic advection associated with the time-varying $\mathrm{KE}$ jet.

By least squares fitting the SST and $\overline{h_{N}}(t)$ time series to Eq. (6), we find $a=2.73 \times 10^{-7} \mathrm{~K} \mathrm{~m}^{-1} \mathrm{~s}^{-1}, \lambda^{-1}=$ 129.2 days, and that the variance for $q(t)$ is equal to $1.734 \times 10^{-14} \mathrm{~K}^{2} \mathrm{~s}^{-2}$. With $q(t)$ in Eq. (6) representing the white noise forcing and assuming it is uncorrelated to the $\overline{h_{N}}(t)$ time series at all frequencies, the power spectrum for $T(t)$ in this case is given by 

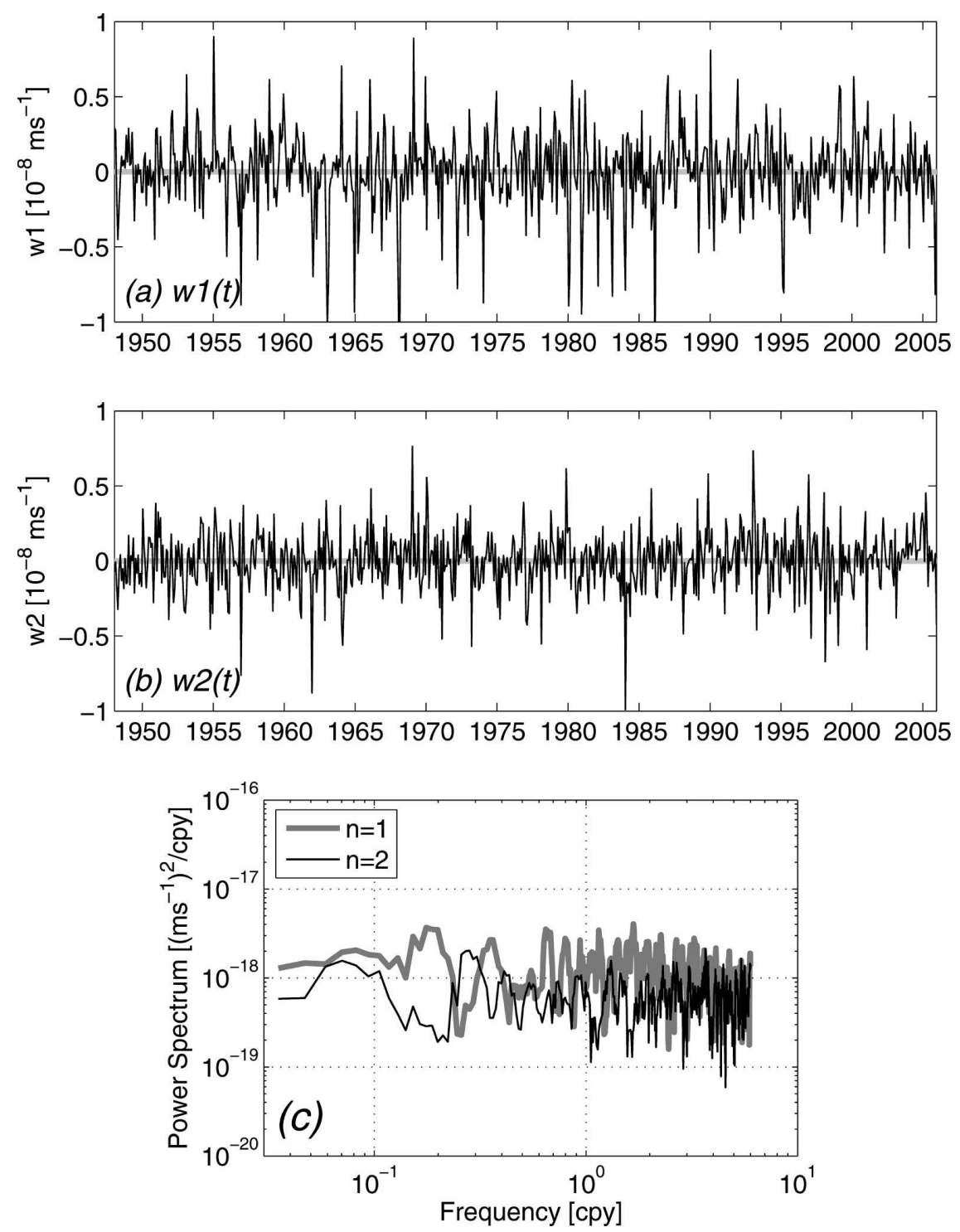

FIG. 7. Time series of wind stress curl along the KE latitude band with the spatial patterns of (a) $\sin (\pi x / W)$ and (b) $\sin (2 \pi x / W)$. (c) Power spectra of the wind stress curl time series shown in (a) and (b).

$$
|\hat{T}(\omega)|^{2}=\frac{a^{2}\left|\widehat{h_{N}}(\omega)\right|^{2}+|\hat{q}(\omega)|^{2}}{\lambda^{2}+\omega^{2}}
$$

where $\omega$ is the frequency and $\wedge$ denotes the Fourier transform. Figure $8 \mathrm{a}$ shows the power spectrum $\left|\widehat{\overline{h_{N}}}(\omega)\right|^{2}$ based on the $\overline{h_{N}}(t)$ time series shown in Fig. $6 \mathrm{~b}$. Using this result and the values for $a, \lambda$, and $|\hat{q}(\omega)|^{2}=$ $0.289 \times 10^{-14}\left(\mathrm{~K} \mathrm{~s}^{-1}\right)^{2} \mathrm{cpy}^{-1}$ derived above, we plot $|\hat{T}(\omega)|^{2}$ in Fig. $8 \mathrm{~b}$ by the solid line. Compared to the SST spectrum from the climate noise model without the oceanic effect (the dashed line in Fig. 8b, same as in Fig. 4), the SST spectrum has $50 \%$ more variance in the 9-16-yr band. Reflecting the dominance of the SSH variations on the decadal time scales, inclusion of the SSH effect has little impact upon the SST signals with frequencies higher than 2 cpy.

A stringent method for testing the significance of the SSH's impact upon the SST signals is to compare the observed SST signals with those hindcast using the $\overline{h_{N}}(t)$ time series alone, namely,

$$
\frac{\partial T_{\mathrm{SSH}}(t)}{\partial t}=a \overline{h_{N}}(t)-\lambda T_{\mathrm{SSH}}(t)
$$

(Schneider and Cornuelle 2005). Because of the thermal damping time-scale $\lambda^{-1}$ is much shorter than the 

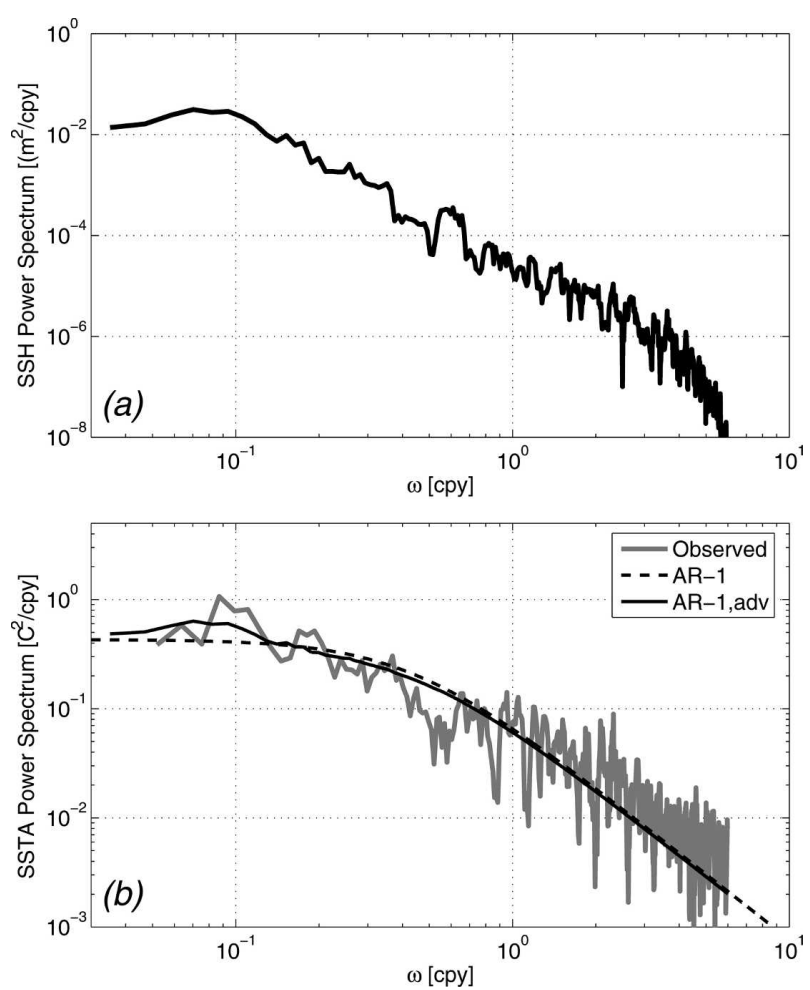

FIG. 8. (a) Power spectrum of the SSH time series forced by the full wind stress curl field (see the solid line in Fig. 6b). (b) Power spectrum of the SST anomalies in the KE band (gray line) and the best fit based on the climate noise model with and without the $\mathrm{SSH}$ effect (solid vs dashed lines).

decadal time scale dominating the $\overline{h_{N}}$ time series; $T_{\mathrm{SSH}}$ derived from Eq. (8) is temporally very similar to the $\overline{h_{N}}$ time series (cf. the thin line in Fig. 9 and the solid line in Fig. 6b). The correlation between $\overline{h_{N}}$ and the observed SST time series (Fig. 3a) is $r=0.297$. To test the significance of this correlation, we compare it to the null hypothesis, namely, a selection of random red noise $\bar{h}(t)$ time series are able to perform as well as the $\overline{h_{N}}$ time series based on the baroclinic Rossby wave dynamics. To do so, we first generate 1000 time series of $\bar{h}(t)$ that have the same first-order autoregressive (AR-1) characteristics as that for $\overline{h_{N}}$ (Fig. 8a). For each $\bar{h}(t)$ time series generated, we derive $T_{\mathrm{SSH}}(t)$ from Eqs. (6) and (8) and calculate its correlation with the observed SST time series. The $95 \%$ highest correlation level from these 1000 trials is 0.258 , indicating that the influence of $\overline{h_{N}}$ upon the SST signals in the KE band is significant above the $95 \%$ confidence level. It is worth noting that while it only explains $9.3 \%$ of the observed monthly SST variance, the $T_{\mathrm{SSH}}(t)$ time series accounts for $27.4 \%$ of the SST variance with time scales longer than $10 \mathrm{yr}$ (see Fig. 9 for the comparison between $T_{\mathrm{SSH}}$ and the low-pass filtered SST time series).

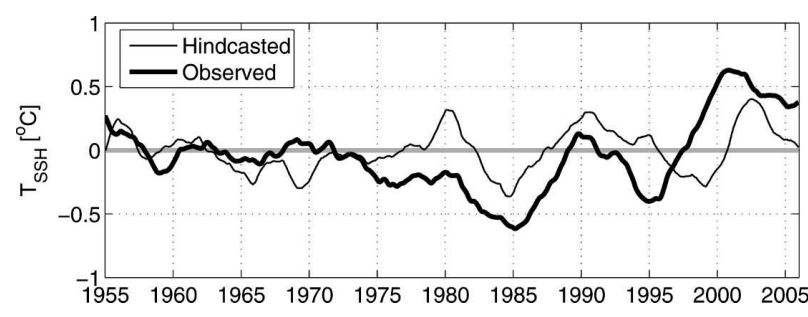

FIG. 9. Low-pass filtered SST anomaly time series observed in the KE band (thick line) (see Fig. 3a for the original time series). The SST time series hindcast by the SSH times series $\overline{h_{N}}(t)$ (thin line); see Eq. (8) for details.

\section{Surface wind response to the KE SST anomalies}

In the preceding section, we showed that inclusion of the oceanic SSH signals in the climate noise model increases the decadal SST variance in the KE band. While this inclusion helps to model the observed spectrum of SST, it does not answer the crucial question of whether this decadal enhancement is due to a purely forced ocean response or a result of the air-sea coupling. To answer this question requires an in-depth examination of the surface wind stress curl field and its connection to the SST anomalies in the KE band.

Because of its strong intrinsic variability, the extent to which the atmosphere responds to midlatitude SST anomalies has been a focus of many observational and modeling studies (e.g., Peng et al. 1997; Barnett et al. 1999; Pierce et al. 2001; Kushnir et al. 2002; Tanimoto et al. 2003). In this study, we adopt the statistical approach proposed by Czaja and Frankignoul $(1999,2002)$ and examine the temporal covariance between the SST anomalies in the $\mathrm{KE}$ band and the basinwide wind stress curl anomalies. Although Czaja and Frankignoul's studies have focused on the North Atlantic basin, their approach has been applied recently by Liu and Wu (2004) and Frankignoul and Sennéchael (2007) to the North Pacific basin. Our present analysis complements these existing studies, and of particular interest to us is how the SST anomalies detected in the KE band impact the wind stress curl field that subsequently drives the SSH changes in the KE band. ${ }^{1}$

The essence of Czaja and Frankignoul's approach is to examine the covariability of an atmospheric variable (here, the surface wind stress curl) and the SST with a

\footnotetext{
${ }^{1}$ Both Liu and $\mathrm{Wu}$ (2004) and Frankignoul and Sennéchael (2007) have investigated the ocean-atmosphere covariability by focusing on the SST signals centered along $40^{\circ} \mathrm{N}$ in the western North Pacific Ocean. As we argued in section 3, despite having less variance, the SST anomalies in the KE band (centered along $35^{\circ} \mathrm{N}$ ) are likely to be more relevant for the air-sea coupled mode in the North Pacific.
} 
(a) $m=-1:$ SST(DJF) vs. curl (NDJ)

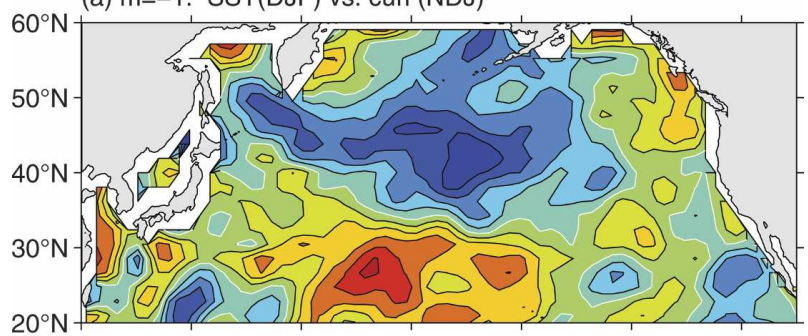

(b) $\mathrm{m}=3$ : SST(DJF) vs. curl (MAM)
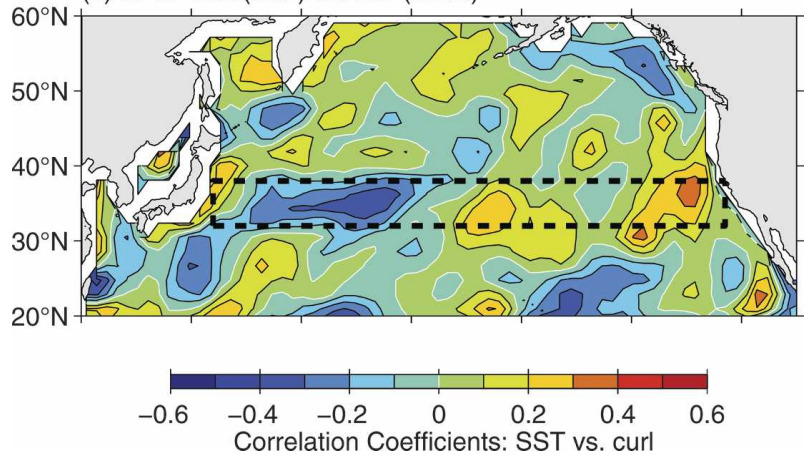

FIG. 10. Lagged correlation between the wintertime (DJF) SST anomalies in the KE band and the North Pacific wind stress curl field: (a) the wind stress curl leads the DJF SST by 1 month, and (b) the wind stress curl lags the DJF SST by 3 months. CIs are 0.1, with the white contours indicating $r=0$. The dashed box indicates the latitudinal band of the KE.

lag that is longer than the intrinsic atmospheric time scale ( $\sim 1$ month) but shorter than the persistence time scale of SST, $\lambda^{-1}$. Before applying this approach, we follow Frankignoul and Sennéchael (2007) and remove by linear regression the Niño-3.4 SST signals from the monthly $\tau(x, y, t)$ time series at all midlatitude grid points. The regression is done on a seasonal basis and works to remove the low-frequency surface wind signals that are teleconnected from the Tropics (Alexander et al. 2002). Figure 10 shows the spatial patterns of lagged correlation $r(x, y, m)$ between the wind stress curl anomalies and the wintertime [DecemberFebruary (DJF)] SST anomalies in the KE region:

$$
r(x, y, m)=\frac{\langle T(t) \operatorname{curl} \tau(x, y, t+m)\rangle}{\sqrt{\left\langle T^{2}(t)\right\rangle\left\langle\operatorname{curl} \tau^{2}(x, y, t+m)\right\rangle}},
$$

where angle brackets denote the ensemble average and $m(>0)$ denotes the SST lead time in months. Here, we focus on the wintertime SST signals because DJF are the months when both the SST and air-sea heat flux anomalies have the largest seasonal amplitude. To better understand the SST's impact on the overlying surface wind field, it is instructive to first examine the spatial pattern when the wind stress curl signal leads the SST signal. Figure 10a shows the $r(x, y, m)$ pattern when $m=-1$ month. The dipolar structure shown in the figure reflects that warm SST anomalies in the KE region are associated with the weakening of the surface westerlies, resulting in a negative (positive) wind stress curl anomaly in the subpolar (subtropical) North Pacific. This dipolar pattern bears a resemblance to those of the leading EOF modes of the decadal sea level pressure anomalies identified by several previous investigators (e.g., Trenberth and Hurrell 1994; Deser and Blackmon 1995; Nakamura et al. 1997). Notice that the values of the correlation coefficient in Fig. 10a are generally high $(|r|>0.6)$, reflecting the dominance over the midlatitude SST forcing by the overlying atmospheric variability.

The spatial pattern of $r(x, y, m)$ becomes very different when the surface wind signal lags that of SST. Figure $10 \mathrm{~b}$ shows the $r(x, y, m)$ pattern when $m=3$ months. ${ }^{2}$ Along the KE band of our interest, warm KE SST anomalies tend to generate an overlying negative wind stress curl anomaly (i.e., a high pressure anomaly) and a downstream positive wind stress curl anomaly (see Fig. 11a). This warm SST downstream low pressure anomaly structure is consistent with the AGCM results that are forced by localized, midlatitude heat flux anomalies (Yulaeva et al. 2001; Sutton and Mathieu 2002). Compared to the $m=-1$ case, the correlation coefficient in Fig. 10b generally has smaller values, suggesting that the dynamical feedback of SST to the overlying atmosphere is relatively weak. Indeed, with each year providing an independent sample (i.e., the number of degrees of freedom at 57), most of the estimated correlation coefficients in the $32^{\circ}-38^{\circ} \mathrm{N}$ band of our interest fall in the confidence level between $90 \%(r=$ $0.22)$ and $95 \%(r=0.26)$.

The spatial pattern presented in Fig. 11a suggests that the SST-induced wind stress curl variability along the KE band has a spatial structure of $\sin \left(2 \pi x W^{-1}\right)$. By adding this feedback component of the wind forcing to the intrinsic atmospheric forcing, we can express the total wind stress curl signal by [recall Eq. (4)]

$$
-\frac{g^{\prime} \operatorname{curl} \tau(x, t)}{\rho_{o} g f}=\sum_{n=1}^{N} \sin \left(\frac{n \pi x}{W}\right) w_{n}(t)+b \sin \left(\frac{2 \pi x}{W}\right) T(t),
$$

\footnotetext{
${ }^{2}$ Spatial patterns similar to Fig. $10 \mathrm{~b}$ are found for $m=1$ and 2 months, but they are generally less well organized spatially. As stressed in Czaja and Frankignoul (2002), $m=3$ here should not be interpreted as a delayed response of the atmosphere to SST by 3 months. Rather, it indicates that the wind stress curl variability over the North Pacific Ocean has a KE SST-induced component that has the persistence of the SST anomalies.
} 


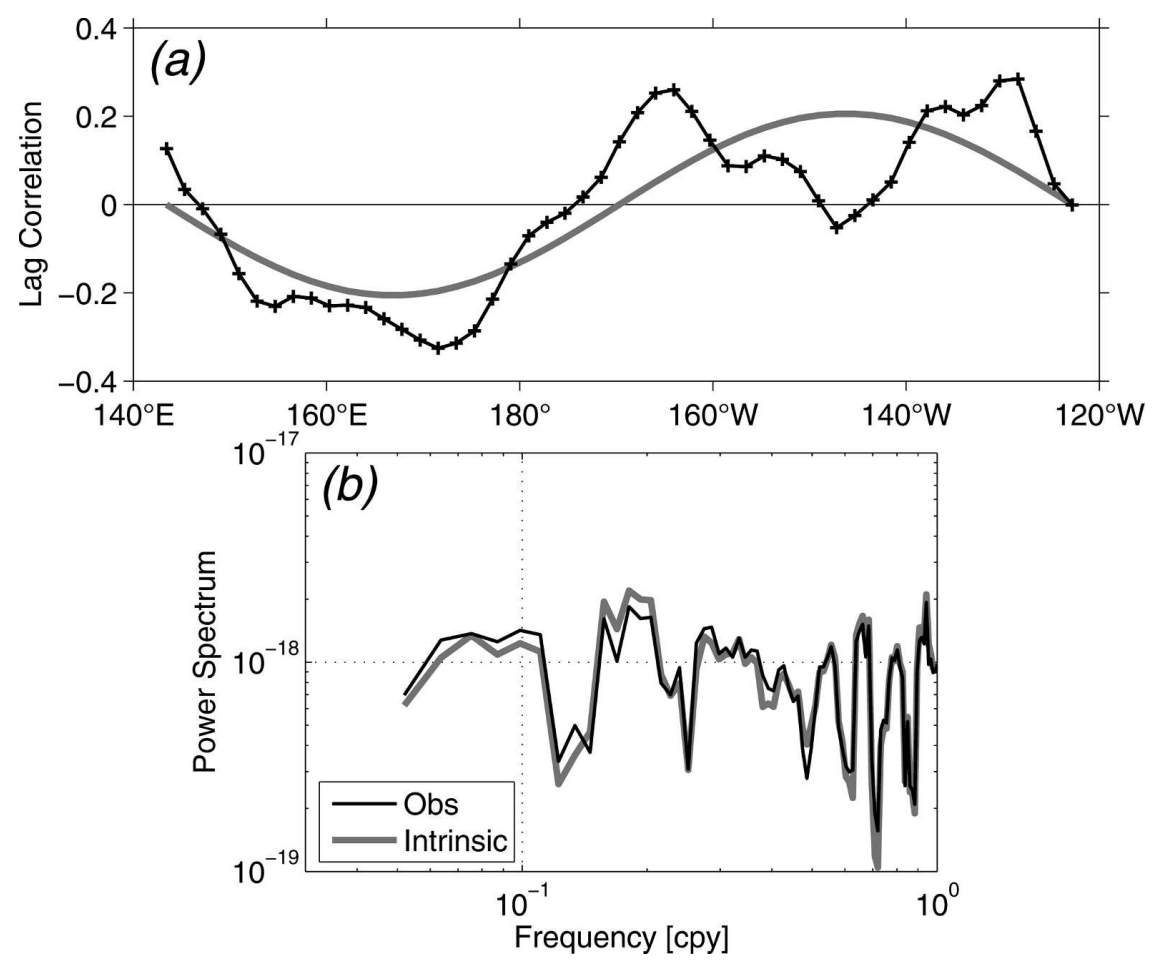

FIG. 11. (a) Correlation along the $32^{\circ}-38^{\circ} \mathrm{N}$ band when the wind stress curl lags the DJF KE SST by 3 months (see the dashed box in Fig. 10b). Solid curve shows the best fit to the $\sin (2 \pi x / W)$ function. (b) Power spectra of the observed wind stress curl forcing $-g^{\prime} \operatorname{curl} \tau / \rho_{o} g f$ (black line) vs the intrinsic wind stress curl forcing $-g^{\prime} \operatorname{curl} \tau / \rho_{o} g f-b T \sin (2 \pi x / W)$ (gray line). The forcing values have been averaged in the eastern half of the $32^{\circ}-38^{\circ} \mathrm{N}$ band.

where $b$ is a coefficient relating the SST anomalies in the $\mathrm{KE}$ band to those in the wind stress curl field along the $32^{\circ}-38^{\circ} \mathrm{N}$ band. For a $1^{\circ} \mathrm{C}$ SST change, a linear regression between the monthly SST and wind stress curl anomalies with the spatial structure of $\sin (2 \pi x$ $W^{-1}$ ) reveals that the curl $\tau$ change is $1.35 \times 10^{-8} \mathrm{~N}$ $\mathrm{m}^{-3}$. Using $g^{\prime}=0.04 \mathrm{~m} \mathrm{~s}^{-2}, g=9.8 \mathrm{~m} \mathrm{~s}^{-2}, \rho_{o}=10^{-3} \mathrm{~kg}$ $\mathrm{m}^{-3}$, and $f=8.34 \times 10^{-5} \mathrm{~s}^{-1}$, this leads to $b=6.64 \times$ $10^{-10} \mathrm{~m} \mathrm{~s}^{-1} \mathrm{~K}^{-1}$.

It is worth commenting on the size of the feedback term $b T \sin \left(2 \pi x W^{-1}\right)$ in Eq. (9). While moderate, this feedback term is not negligible and this is particularly true for the wind stress curl signals with a decadal time scale. Averaged over the eastern half of the $32^{\circ}-38^{\circ} \mathrm{N}$ band, the power of the observed decadal wind stress curl forcing $-g^{\prime} \operatorname{curl} \tau / \rho_{o} g f$ is $1.44 \times 10^{-18}\left(\mathrm{~m} \mathrm{~s}^{-1}\right)^{2} \mathrm{cpy}^{-1}$ (see Fig. 11b, solid line). The power for the "feedback" wind stress curl forcing averaged in the same region can be estimated by $2 b^{2}|\hat{T}(\omega)|^{2} / \pi$. Using $b=6.64 \times 10^{-10}$ $\mathrm{m} \mathrm{s}^{-1} \mathrm{~K}^{-1}$ and $|\hat{T}(\omega)|^{2}=1 \mathrm{~K}^{2} \mathrm{cpy}^{-1}$ based on Fig. $3 \mathrm{~b}$, we have $2 b^{2}|\hat{T}(\omega)|^{2} \pi=0.28 \times 10^{-18}\left(\mathrm{~m} \mathrm{~s}^{-1}\right)^{2} \mathrm{cpy}^{-1}$, indicating that the SST-induced wind stress curl forcing can explain close to $20 \%$ of the observed decadal variance. A calculation of the area-averaged spectrum shows that $-g^{\prime} \operatorname{curl} \tau / \rho_{o} g f-b T \sin \left(2 \pi x W^{-1}\right)$ has a decadal power at $1.23 \times 10^{-18}\left(\mathrm{~m} \mathrm{~s}^{-1}\right)^{2} \mathrm{cpy}^{-1}$ (Fig. 11b, gray line). This reduction in the decadal spectral power confirms that the observed wind stress curl data indeed contain a decadal feedback component that can be traced back to the KE SST anomalies.

\section{Coupled versus uncoupled variability}

By relating the SST variability to that of the surface wind stress curl field in the previous section, we obtain the following set of equations governing the SST changes in the KE band:

$$
\begin{aligned}
\frac{\partial h(x, t)}{\partial t}-c_{R} \frac{\partial h(x, t)}{\partial x} & =-\frac{g^{\prime} \operatorname{curl} \tau}{\rho_{o} g f}, \\
\frac{\partial T(t)}{\partial t} & =a \overline{h(t)}-\lambda T(t)+q(t),
\end{aligned}
$$

and

$$
\begin{aligned}
-\frac{g^{\prime} \operatorname{curl} \tau}{p_{o} g f}= & \sum_{n=1}^{2} \sin \left(\frac{n \pi x}{W}\right) w_{n}(t) \\
& +b \sin \left(\frac{2 \pi x}{W}\right) T(t) .
\end{aligned}
$$


Notice that in Eq. (12), we have replaced the original $N$ in Eq. (9) by 2, because the higher spatial modes, as we discussed in section 4a, exert little impact upon the SSH signals averaged in the KE band. For brevity, we have also replaced $h_{2}$ (i.e., the SSH signal induced by the two leading spatial modes of the wind forcing) by $h$. By explicitly separating the wind stress forcing into the intrinsic and feedback components in Eq. (12), we will assume in this section that both $w_{1}(t)$ and $w_{2}(t)$ have white spectra and focus on the coupling effect of the SST-induced wind stress curl forcing.

It is worth commenting that Eqs. (10)-(12) resemble the set of equations put forth previously by Jin (1997) in his theoretical study of the North Pacific decadal variability. While similar in form, the physical processes assumed by Jin (1997), especially those of Eqs. (11) and (12), are different from the ones derived in this study. Given a warm SST anomaly in the KE, Jin (1997) assumes that it generates a downstream high pressure anomaly and, hence, an enhanced Ekman pumping. As the positive SSH anomalies generated by the enhanced Ekman pumping reach the western boundary, Jin (1997) argues that they generate a southward interior geostrophic flow $\left(v^{\prime}<0\right)$ that will change the sign of the KE SST anomaly through interior geostrophic heat advection (i.e., $-v^{\prime} \partial T_{m} / \partial y<0$, where $T_{m}$ is the mean surface ocean temperature). From the statistical analysis conducted in section 5, we find that a warm SST anomaly in the KE band works to generate a downstream low pressure anomaly and, hence, an enhanced Ekman suction. The latter lowers the SSH in the eastern North Pacific and tends to weaken the KE jet as the SSH anomalies propagate westward. By weakening the $\mathrm{KE}$ jet and shifting it southward, the Ekman suctioninduced negative SSH anomalies result in cold SST anomalies in the KE region, thereby switching the phase of the coupled oscillation.

\section{a. Air-sea uncoupled case $(b=0)$}

Before exploring the coupled case, it is instructive to examine the case where there is no SST feedback to the atmosphere. In this case, $b=0$ and, upon substituting Eq. (12) into Eq. (3), we have

$$
h(x, t)=-\frac{1}{c_{R}} \int_{0}^{x} \sum_{n=1}^{2} \sin \left(\frac{n \pi x^{\prime}}{W}\right) w_{n}\left(t+\frac{x-x^{\prime}}{c_{R}}\right) d x^{\prime} .
$$

Taking its Fourier transform

$$
\hat{h}(x, \omega)=-\sum_{n=1}^{2} \frac{\hat{w}_{n}(\omega)}{c_{R}} \int_{0}^{x} \sin \left(\frac{n \pi x^{\prime}}{W}\right) e^{i \omega\left(x-x^{\prime}\right) / c_{R}} d x^{\prime},
$$
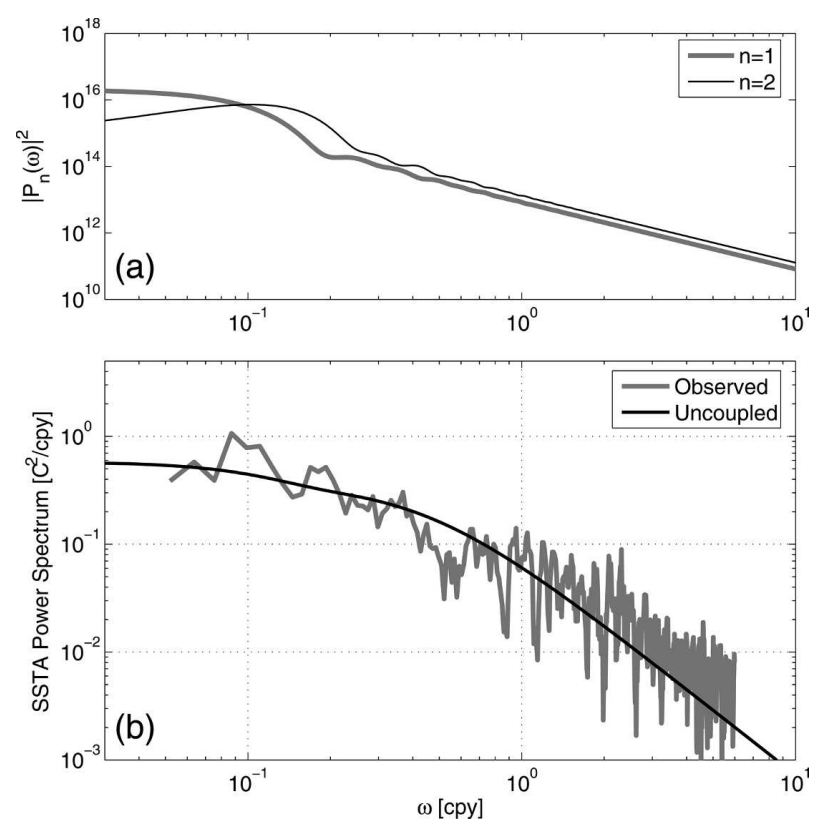

Fig. 12. (a) Squared amplitudes of $P_{1}(\omega)$ and $P_{2}(\omega)$ as a function of frequency. (b) Power spectrum of the observed SST anomalies in the KE band (gray line). Power spectrum of SST forced by the white noise surface wind and thermal forcing under the air-sea uncoupled scenario (black line); see Eq. (17).

we can express the Fourier transform for the SSH anomaly averaged in the KE band by

$$
\overline{\hat{h}}(\omega) \equiv \frac{1}{L} \int_{-W}^{-W+L} \hat{h}(x, \omega) d x=\sum_{n=1}^{2} P_{n}(\omega) \hat{w}_{n}(\omega),
$$

where $P_{n}(\omega)$ is given by

$$
\begin{aligned}
P_{n}(\omega)= & \frac{1}{2 L c_{R}}\left[\frac{W}{n \pi \alpha_{n+}}\left(e^{i n \pi L / W}-1\right) e^{-i n \pi}\right. \\
& +\frac{W}{n \pi \alpha_{n-}}\left(e^{-i n \pi L / W}-1\right) e^{i n \pi} \\
& \left.-\left(\frac{1}{\alpha_{n+}}-\frac{1}{\alpha_{n-}}\right) \frac{c_{R}}{\omega}\left(e^{i \omega L / c_{R}}-1\right) e^{-i \omega W / c_{R}}\right],
\end{aligned}
$$

and $\alpha_{n \pm}=i\left(-\omega / c_{R} \pm n \pi / W\right)$. For $\bar{h}(\omega)$ in Eq. (14), $P_{n}(\omega)$ serves as a frequency-dependent filter to the wind forcing that has the spatial structure $\sin (n \pi x / W)$. Figure 12a shows the squared amplitude of $P_{1}(\omega)$ and $P_{2}(\omega)$ as a function of frequency. Reflecting the integrating nature of the forced Rossby wave dynamics, both terms are highly effective low-pass filters.

Taking the Fourier transform of Eq. (11) and using Eq. (14), we have

$$
(\lambda+i \omega) \hat{T}(\omega)=a \sum_{n=1}^{2} P_{n}(\omega) \hat{w}_{n}(\omega)+\hat{q}(\omega) .
$$


TABLE 1. Parameter values appropriate for the midlatitude North Pacific Ocean.

\begin{tabular}{ll}
\hline \hline Parameter & \multicolumn{1}{c}{ Value } \\
\hline $\mathrm{c}_{\mathrm{R}}$ & $0.033 \mathrm{~m} \mathrm{~s}^{-1}$ \\
$\mathrm{f}$ & $8.34 \times 10^{-5} \mathrm{~s}^{-1}$ \\
$\mathrm{~W}$ & $95^{\circ} \mathrm{lon}$ \\
$\mathrm{L}$ & $40^{\circ} \mathrm{lon}$ \\
$\lambda$ & $1(129.2 \mathrm{day})^{-1}$ \\
$\mathrm{a}$ & $2.73 \times 10^{-7} \mathrm{~K} \mathrm{~m}^{-1} \mathrm{~s}^{-1}$ \\
$\left|\widehat{w_{1}}(\omega)\right|^{2}$ & $1.127 \times 10^{-18}\left(\mathrm{~m} \mathrm{~s}^{-1}\right)^{2} \mathrm{cpy}^{-1}$ \\
$\left|\widehat{w_{2}}(\omega)\right|^{2}$ & $0.643 \times 10^{-18}\left(\mathrm{~m} \mathrm{~s}^{-1}\right)^{2} \mathrm{cpy}^{-1}$ \\
$|\widehat{\mathrm{q}}(\omega)|^{2}$ & $2.89 \times 10^{-15}\left(\mathrm{~K} \mathrm{~s}^{-1}\right)^{2} \mathrm{cpy}^{-1}$ \\
$\mathrm{~b}$ & $6.64 \times 10^{-10} \mathrm{~m} \mathrm{~s}^{-1} \mathrm{~K}^{-1}$ \\
\hline
\end{tabular}

With the assumption of $w_{n}(t)$ and $q(t)$ being independent white noise forcing, the power spectrum for the SST anomalies in this uncoupled case can be calculated by

$$
\begin{aligned}
|\hat{T}(\omega)|_{\text {uncoupled }}^{2}= & \frac{1}{\lambda^{2}+\omega^{2}} \\
& \times\left[a^{2} \sum_{n=1}^{2}\left|P_{n}(\omega)\right|^{2}\left|\hat{w}_{n}(\omega)\right|^{2}+|\hat{q}(\omega)|^{2}\right] .
\end{aligned}
$$

Using the parameter values derived in the previous sections (Table 1), we plot $|\hat{T}(\omega)|_{\text {uncoupled }}^{2}$ by the solid line in Fig. 12b and compare it to the observed SST spectrum in the KE band. From the figure, it is clear that the uncoupled model is inadequate to explain the decadal spectral peak of our interest. It is worth noting that Eq. (17) contains the "spatial resonance" mechanism proposed by several previous investigators (e.g., Frankignoul et al. 1997; Saravanan and McWilliams 1998; Neelin and Weng 1999). For example, $\left|P_{2}(\omega)\right|^{2}$ has a spectral peak around 8 yr (Fig. 12a), and this peak would have shown up in $|\hat{T}(\omega)|_{\text {uncoupled }}^{2}$ if the $n=2$ wind forcing had dominated the $n=1$ wind and heat flux forcings in Eq. (17). In other words, given the physical parameters appropriate for the midlatitude North $\mathrm{Pa}$ cific, the spatial resonance mechanism alone, without the SST feedback to the atmosphere, is insufficient to generate the preferred decadal time scale detected in the KE's SST field.

\section{b. Air-sea coupled case $(b \neq 0)$}

The analysis pursued above can be easily extended to include the SST feedback (i.e., $b \neq 0$ ). In this case, Eq. (14) is replaced by

$$
\overline{\hat{h}}(\omega)=\sum_{n=1}^{2} P_{n}(\omega) \hat{w}_{n}(\omega)+b P_{2}(\omega) \hat{T}(\omega),
$$
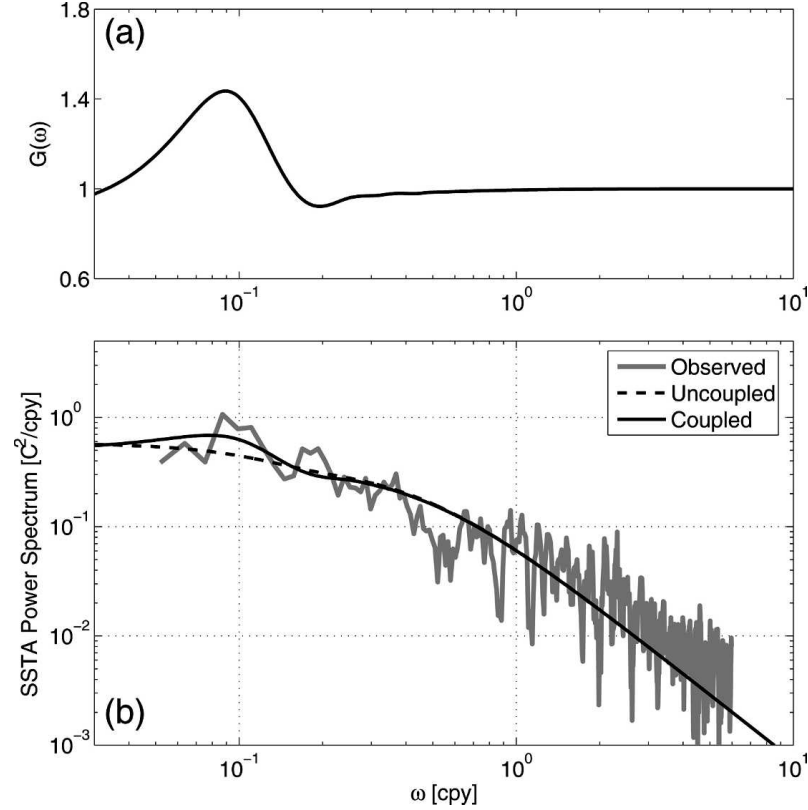

Fig. 13. (a) Amplitude of the amplification factor $G(\omega)$ as a function of frequency. (b) Power spectrum of the observed SST anomalies in the KE band (gray line). Power spectrum of SST under the air-sea coupled scenario (solid line); see Eq. (20). Power spectrum of SST under the air-sea uncoupled scenario (dashed line); see Eq. (17).

and Eq. (16) by

$$
\left[\lambda+i \omega-a b P_{2}(\omega)\right] \hat{T}(\omega)=a \sum_{n=1}^{2} P_{n}(\omega) \hat{w}_{n}(\omega)+\hat{q}(\omega) .
$$

From Eq. (19), it is easy to derive

$|\hat{T}(\omega)|_{\text {coupled }}^{2}=\left|\frac{\lambda+i \omega}{\lambda+i \omega-a b P_{2}(\omega)}\right|^{2}|\hat{T}(\omega)|_{\text {uncoupled }}^{2}$

Equation (20) indicates that the SST spectrum in the coupled case is equal to the spectrum of the uncoupled case [i.e., Eq. (17)] amplified by $G(\omega)=\mid(\lambda+i \omega) /(\lambda+$ $\left.i \omega-a b P_{2}\right)\left.\right|^{2}$. In Fig. 13a, we plot the amplification factor $G(\omega)$ as a function of frequency. For parameter values relevant to the North Pacific, it is shown in the appendix that the largest amplification occurs when the period of the coupled mode is at

$$
T_{\text {optimal }} \simeq \frac{W}{c_{R}} \frac{1}{(1-\epsilon)},
$$

where $\epsilon$ is a small correction term defined in Eq. (A5) in the appendix. Using the parameter values listed in Table 1 , we have $\epsilon=0.21$ and $T_{\text {optimal }} \simeq 10.4 \mathrm{yr}$, in agreement with the peak in $G(\omega)$.

Aside from the correction term $\epsilon$, the physical inter- 
pretation of $T_{\text {optimal }}=W / c_{r}(=8.23 \mathrm{yr})$ in Eq. (21) is straightforward. With the spatial structure of the SSTinduced wind forcing being $\sin \left(2 \pi x W^{-1}\right)$, the optimal coupling occurs when the time required for the windinduced SSH anomaly to travel from the center of the maximum forcing (at $x=-W / 4$ ) to the center of the $\mathrm{KE}$ band (at $x \simeq-3 W / 4$ ) is equal to half of the wave period. In such a case, an initial warm SST anomaly, for example, would induce a positive $\operatorname{curl} \tau$ anomaly in the eastern half of the basin, generating negative SSH anomalies through Ekman divergence. As the negative SSH anomalies reach the center of the KE band in the western half of a wave period later, they cause the regional SST to decrease, which, in turn, switches the sign of the curl $\tau$ anomaly in the east. The correction term $\epsilon$ in Eq. (21) accounts for deviations from this simple physical picture due to the fact that the SST-induced wind forcing is spatially a sine function (instead of a $\delta$ function) and that the KE band does not occupy the exact western half of the North Pacific basin.

In Fig. 13b, we compare the spectra of $|\hat{T}(\omega)|_{\text {coupled }}^{2}$ (the black line) versus $|\hat{T}(\omega)|_{\text {uncoupled }}^{2}$ (the dashed line). In contrast to the "red" spectrum found in the uncoupled case, $|\hat{T}(\omega)|_{\text {coupled }}^{2}$ now has a decadal spectral peak due to the amplification through $G(\omega)$. Over the decadal frequency band, the spectral shape of $|\hat{T}(\omega)|_{\text {coupled }}^{2}$ agrees closely with the full forcing case (the case in which $|\hat{h}(\omega)|^{2}$ was calculated based on the observed wind forcing; cf. the black line in Fig. 8b), indicating the air-sea coupling described in this section is a likely explanation for the enhanced decadal SST variability observed in the KE band. Like Fig. 8b, the modeled decadal spectral peak in Fig. 13b still underestimates the observed spectral peak. A possible reason for this underestimation is discussed in section 7 .

\section{c. Parameter sensitivity}

Given the importance of $G(\omega)$ for the coupled SST variability, it is useful to comment on its sensitivity to the relevant parameters. Once the basin size $W$ and the Rossby wave speed $c_{R}$ are fixed, the peak in $\mathrm{G}(\omega)$, or $T_{\text {optimal }}$, is dependent only on the chosen length of the KE band $L$. Because $L$ only changes $\epsilon$, a small correction term in Eq. (21), its impact on $T_{\text {optimal }}$ is rather limited. To quantify this statement, we compare in Fig. 14a the $G(\omega)$ values when $L$ is lengthened/shortened by $10^{\circ}$ from its nominal value of $40^{\circ}$ in longitude. Despite the $25 \%$ change in $\mathrm{L}$, the change in $T_{\text {optimal }}$ is less than $9 \%\left(T_{\text {optimal }}=12.1,11.2\right.$, and $10.5 \mathrm{yr}$ for $L=30^{\circ}, 40^{\circ}$, and $50^{\circ}$, respectively, in Fig. 14a). In other words, the dominance of the 10-yr signals found in Fig. 13b is a robust feature insensitive to our choice of $L$.
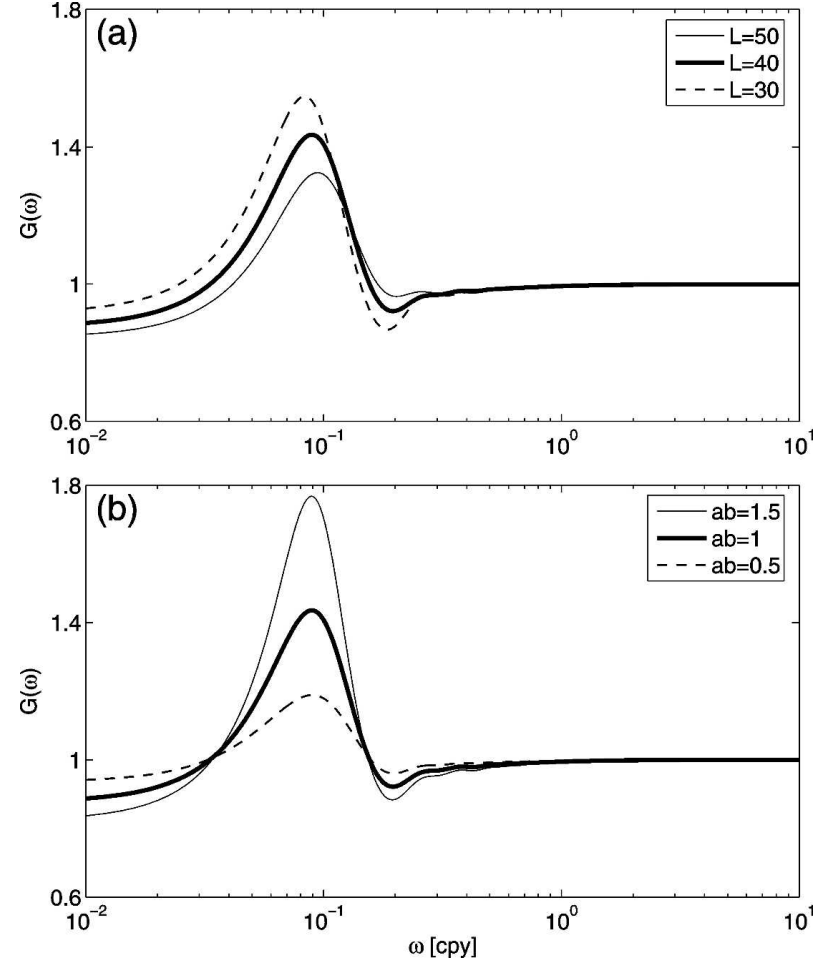

FIG. 14. Amplitudes for the amplification factor $G(\omega)$ when (a) the length of the KE band $L$ and (b) the coupled parameter $a b$ are changed parametrically. In (b), $a b=1$ denotes the case in which $a b$ is given by the values listed in Table 1 and $a b=1.5(0.5)$ denotes the case in which $a b$ is enhanced (reduced) by $50 \%$.

While having no influence on $T_{\text {optimal }}$, parameters $a$ and $b$ affect the amplitude of $G(\omega)$ through their product $a b$. For the decadal frequency band of our interest, the amplitude of $G(\omega)$ increases with increasing $a b$ (see Fig. 14b). Recall that $a$ is the parameter coupling the SSH anomalies to the SST anomalies in the KE band, and $b$ is the parameter coupling the SST anomalies to the wind stress curl anomalies. So, strengthening either of the coupling parameters would enhance the decadal spectral peak in $|\hat{T}(\omega)|_{\text {coupled. }}^{2}$.

\section{Discussions and summary}

The objective of the present study is to clarify the nature underlying the observed decadal variability in the midlatitude North Pacific. To achieve this objective, we examined in detail the long-term SST signals in the Kuroshio Extension (KE) region of $32^{\circ}-38^{\circ} \mathrm{N}$ and $142^{\circ} \mathrm{E}-180^{\circ}$. In addition to being the region where the ocean circulation is most variable in the North Pacific, the $\mathrm{KE}$ is also where the largest heat/moisture exchanges take place across the air-sea interface. Over 
the past $58 \mathrm{yr}$ covered in this analysis, SST signals in the $\mathrm{KE}$ region are dominated by changes with periods of $\sim 10$ and $\sim 50$ yr. Given the length of the available data, only the decadal signals are explored in this study [for pentadecadal signals, see Minobe (1997)].

Two issues are of particular interest to this study: 1 ) what role does the ocean dynamics play in contributing to the observed decadal SST signals, and 2) to what extent is the observed decadal SST variability a consequence of coupling between the midlatitude ocean and atmosphere. To answer these questions, we began by testing the climate noise scenario, in which no ocean dynamics was considered. While providing a reasonable overall spectral shape of the observed SST spectrum, the simple climate noise model fails to capture the decadal spectral peak of our interest.

To examine the advective effect of the ocean circulation, we extended the climate noise model to include the sea surface height (SSH) signals averaged in the KE region. Satellite altimeter measurements of the past decade have shown that the low-frequency KE variability is dominated by concurrent changes in the strength and path of the KE jet. A strengthened (weakened) KE jet tends to be accompanied by a northerly (southerly) path, giving rise to a positive (negative) regional SSH anomaly. By adopting a linear vorticity model with the baroclinic Rossby wave dynamics, we hindcast the SSH changes forced by the wind stress data from the NCEPNCAR reanalysis. Due to the integrating nature of the wave dynamics, we found that the wind-induced SSH signals in the KE region have a broad spectral peak in the decadal-to-interdecadal frequency band, in agreement with many of the previous studies of the lowfrequency KE variability (e.g., Miller et al. 1998; Deser et al. 1999; Seager et al. 2001; Schneider et al. 2002; Qiu 2003). Much of the modeled SSH variability was found to be induced by the basin-scale wind stress curl forcing with the lowest two spatial modes.

Inclusion of the SSH signals in the climate noise model helps to explain the observed decadal spectral peak in the SST spectrum, although the level of power is still underestimated. One possibility for this underestimation is that the linear Rossby wave dynamics does not account for the SSH signals. Our recent analysis of satellite altimetry data revealed that while the linear Rossby wave dynamics modeled adequately the phases of the SSH changes in the KE, it underestimated the amplitude by $\sim 40 \%$ (Qiu and Chen 2005). As the wind-induced, negative SSH anomalies propagated from the east, altimetry measurements show that they tend to weaken the stability of the KE jet, enhancing the regional mesoscale eddy variability and further low- ering the regional SSH signals. This rectified effect of eddy-mean flow interaction is also emphasized in the recent study by Taguchi et al. (2007). By analyzing the output from the high-resolution Ocean Model for the Earth Simulator (OFES), Taguchi et al. found a covariability between the large-scale $\mathrm{KE}$ changes that are wind driven and the "frontal-scale" intrinsic changes of the recirculation gyre that enhance the wind-driven SSH signals. Notice that if such a rectified effect of the intrinsic ocean variability could be "parameterized" through increasing the value for the coupling parameter $a$ in Eq. (6), the magnitude of the modeled decadal spectral peak would be enhanced and the comparison between the modeled and observed SST spectra improved.

The presence of a localized spectral peak per se does not imply the existence of an air-sea coupled mode. To clarify the mechanism responsible for the observed decadal spectral peak, we adopted the statistical approach of Czaja and Frankignoul $(1999,2002)$ and examined the lagged correlation between the wintertime SST anomalies in the KE band and the basin-scale wind stress curl anomalies. When the SST signals lead by 3 months (a time scale longer than the intrinsic atmospheric variability and shorter than the SST decorrelation time scale), the responding wind stress curl field has a negative anomaly (i.e., a positive pressure anomaly) over the KE band and a positive anomaly (a negative pressure anomaly) in the eastern half of the basin. This response pattern of the wind stress curl field is very different from the wind stress curl pattern that forces the KE SST signals.

The importance of the air-sea coupling is explored in this study by dividing the wind stress curl forcing into those associated with the intrinsic atmospheric variability and those induced by the SST signals in the KE band. In the absence of the SST feedback, the intrinsic atmospheric forcing generates low-frequency changes in the SSH signals in the KE band. While this forced oceanic variability enhances the SST spectral level in the decadal and longer frequency band, it fails to capture the decadal SST peak detected in the observations. When the SST feedback is present, a warm SST anomaly would generate positive wind stress curl in the eastern part of the basin, resulting in negative local SSH anomalies through Ekman divergence. As these windforced SSH anomalies propagate into the $\mathrm{KE}$ region in the west, they shift the KE jet southward and alter the sign of the preexisting SST anomalies. In this coupled scenario, it is the adjustment of the upper ocean through baroclinic Rossby waves that provides the memory for the system. Given the spatial pattern of the 
SST-induced wind stress curl forcing, the optimal coupling in the midlatitude North Pacific occurs at a period slightly longer than the basin-crossing time of the baroclinic Rossby waves along the KE latitude $(\sim 8.23 \mathrm{yr})$. We believe that it is this coupled mechanism that contributes to the increase in variance around the decadal time scale in the SST field observed along the KE band.

It is worth noting that several coupled GCM studies of the midlatitude North Pacific have identified air-sea coupled modes involving the KE system with a period ranging from 16 to $20 \mathrm{yr}$ (e.g., Latif and Barnett 1994, 1996; Barnett et al. 1999; Pierce et al. 2001; Kwon and Deser 2007). The period of these coupled modes is clearly longer than the 10 -yr period identified in the present study. Due to the model resolution, the KE jet in these climate models tends to commonly separate from the Japan coast at $\sim 40^{\circ} \mathrm{N}$, which is $5^{\circ}$ farther north than the observed KE separation latitude (Hurlburt et al. 1996). Given that the baroclinic Rossby wave speed depends sensitively on latitude [e.g., $c_{R}=0.033$ $\mathrm{m} \mathrm{s}^{-1}$ along $35^{\circ} \mathrm{N}$ versus $0.020 \mathrm{~m} \mathrm{~s}^{-1}$ along $40^{\circ} \mathrm{N}$; see Fig. 7 in (Qiu 2003)], it is possible that a mechanism similar to that described in this study may be at work for the coupled variability in the existing CGCM runs.

Finally, we note that although the variance of the coupled SST mode is modest in comparison to the total SST variance in the KE region, the fact that the SSH signals constitute a deterministic forcing can have a large impact upon the predictability of the western North Pacific SST signals (Schneider and Miller 2001; Scott and Qiu 2003). It will be interesting for future studies to explore whether the SST predictability could benefit from incorporating the SST feedback onto the basin-scale wind stress forcing.

Acknowledgments. This study benefited from the discussions with Claude Frankignoul, Rob Scott, and Michael Alexander. Detailed comments made by the anonymous reviewers helped improve an early version of the manuscript. The surface wind stress and heat flux data were provided by the National Centers for Environmental Prediction and the merged T/P, Jason-1, and ERS-1/-2 altimeter data by the CLS Space Oceanography Division as part of the Environment and Climate EU ENACT project. We acknowledge support from NSF (OCE-0220680) and NASA (Contract 1207881) for B.Q. and S.C. and NSF (OCE-0550233), NOAA (NA17RJ1231), and DOE (DE-FG02-04ER63862) for N.S.

\section{APPENDIX}

\section{Optimal Amplification Period for Coupling}

As we derived in Eq. (20), amplification of the SST spectrum in the air-sea coupled case is determined by the factor

$$
G(\omega)=\left|\frac{\lambda+i \omega}{\lambda+i \omega-a b P_{2}(\omega)}\right|^{2} .
$$

With $\lambda$ dominating over $\omega$ and $\left|a b P_{2}(\omega)\right|$ in the lowfrequency band of our interest, finding maximum $G(\omega)$ becomes equivalent to finding the maximum in the real part of $P_{2}(\omega): \operatorname{Re}\left[P_{2}(\omega)\right]$. From Eq. (15), we have

$$
\operatorname{Re}\left[P_{2}(\omega)\right]=\frac{1}{\omega L\left[\left(\frac{\omega}{c_{R}}\right)^{2}-\left(\frac{2 \pi}{W}\right)^{2}\right]}\left\{\frac{2 \pi}{W} \sin \left(\frac{\omega W}{c_{R}}\right)-\frac{2 \pi}{W} \sin \left(\frac{\omega(W-L)}{c_{R}}\right)-\frac{\omega}{c_{R}} \sin \left(\frac{2 \pi L}{W}\right)\right\}
$$

Let $\operatorname{Re}\left[P_{2}(\omega)\right] \equiv A(\omega) / B(\omega)$, the maximum in $\operatorname{Re}$ $\left[P_{2}(\omega)\right]$ can be found by solving

$$
B(\omega) \frac{\partial}{\partial \omega} A(\omega)-A(\omega) \frac{\partial}{\partial \omega} B(\omega)=0 .
$$

With $\omega=2 \pi \mathrm{c}_{R} / W$ being a regular singular point, it is useful to rewrite $\omega$ as $\omega \equiv 2 \pi \mathrm{c}_{R} / W+\omega^{\prime}$ and solve Eq. (A3) using the Taylor expansion with regard to $\omega^{\prime}$. By truncating high-order terms in $\omega^{\prime}$ and ignoring terms of small values, we derive the following expression for $\omega^{\prime}$ :

$$
\begin{aligned}
\omega^{\prime} \simeq & -\frac{9 c_{R}}{4 \pi W}\left[1-\left(\frac{W-L}{W}\right) \cos \left(\frac{2 \pi L}{W}\right)\right. \\
& \left.+\frac{2 \pi}{3}\left(\frac{W-L}{W}\right)^{2} \sin \left(\frac{2 \pi L}{W}\right)\right] .
\end{aligned}
$$

Using Eq. (A4), we find the optimal amplification for coupling occurs at the period

$$
T_{\text {optimal }}=\frac{2 \pi}{2 \pi c_{R} / W+\omega^{\prime}} \equiv \frac{W}{c_{R}} \frac{1}{(1-\epsilon)},
$$

where

$$
\begin{aligned}
\epsilon \simeq & \frac{9}{8 \pi^{2}}\left[1-\left(\frac{W-L}{W}\right) \cos \left(\frac{2 \pi L}{W}\right)\right. \\
& \left.+\frac{2 \pi}{3}\left(\frac{W-L}{W}\right)^{2} \sin \left(\frac{2 \pi L}{W}\right)\right] .
\end{aligned}
$$

Notice that $\omega^{\prime}$ is positive definite, indicating that the optimal amplification for coupling always occurs at a period longer than $W / c_{R}$. Also, when $W / 4<L<W / 2$ 
(as is the case for the KE band), $\epsilon$ decreases with increasing $L$. In other words, $T_{\text {optimal }}$ tends to shorten as $L$ increases (see Fig. 14a).

\section{REFERENCES}

Alexander, M. A., I. Bladé, M. Newman, J. R. Lanzante, N.-C. Lau, and J. D. Scott, 2002: The atmospheric bridge: The influence of ENSO teleconnections on air-sea interaction over the global oceans. J. Climate, 15, 2205-2231.

Barnett, T. P., D. W. Pierce, R. Saravanan, N. Schneider, D. Dommenget, and M. Latif, 1999: Origins of the midlatitude Pacific decadal variability. Geophys. Res. Lett., 26, 1453-1456.

Bjerknes, J., 1964: Atlantic air-sea interaction. Advances in Geophysics, Vol. 10, Academic Press, 1-182.

Czaja, A., and C. Frankignoul, 1999: Influence of the North Atlantic SST on the atmospheric circulation. Geophys. Res. Lett., 26, 2969-2972.

$\longrightarrow$, and — 2002: Observed impact of Atlantic SST on the North Atlantic oscillation. J. Climate, 15, 606-623.

Deser, C., and M. L. Blackmon, 1995: On the relationship between tropical and North Pacific sea surface variations. $J$. Climate, 8, 1677-1680.

— M. A. Alexander, and M. S. Timlin, 1999: Evidence for a wind-driven intensification of the Kuroshio Current Extension from the 1970s to the 1980s. J. Climate, 12, 1697-1706.

,-- , and -2003 : Understanding the persistence of sea surface temperature anomalies in midlatitude. J. Climate, 16, $57-72$.

Dewar, W. K., 2001: On ocean dynamics in midlatitude climate. $J$. Climate, 14, 4380-4397.

Dommengnet, D., and M. Latif, 2002: Analysis of observed and simulated SST spectra in the midlatitudes. Climate Dyn., 19, 277-288.

Ducet, N., P.-Y. Le Traon, and G. Reverdin, 2000: Global highresolution mapping of ocean circulation from TOPEX/ Poseidon and ERS-1 and -2. J. Geophys. Res., 105, $19477-$ 19498.

Frankignoul, C., and K. Hasselmann, 1977: Stochastic climate models. II: Application to sea-surface temperature variability and thermocline variability. Tellus, 29, 284-305.

— cific SST anomalies on the atmospheric circulation. J. Climate, 20, 592-606.

_, P. Muller, and E. Zorita, 1997: A simple model of the decadal response of the ocean to stochastic wind stress forcing. $J$. Phys. Oceanogr., 27, 1533-1546.

Fu, L.-L., and B. Qiu, 2002: Low-frequency variability of the North Pacific Ocean: The roles of boundary- and wind-driven baroclinic Rossby waves. J. Geophys. Res., 107, 3220, doi:10.1029/2001JC001131.

Hasselmann, K., 1976: Stochastic climate models. I: Theory. Tellus, 28, 473-485.

Hogg, A. M., P. D. Killworth, J. R. Blundell, and W. K. Dewar, 2005: Mechanisms of decadal variability of the wind-driven ocean circulation. J. Phys. Oceanogr., 35, 512-531.

Hurlburt, H. E., A. J. Wallcraft, W. J. Schmitz, P. J. Hogan, and E. J. Metzger, 1996: Dynamics of the Kuroshio/Oyashio current system using eddy-resolving models of the North Pacific Ocean. J. Geophys. Res., 101, 941-976.

Jin, F.-F., 1997: A theory of interdecadal climate variability of the
North Pacific ocean-atmosphere system. J. Climate, 10,18211835.

Kelly, K. A., 2004: The relationship between oceanic heat transport and surface fluxes in the western North Pacific: 19702000. J. Climate, 17, 573-588.

Kistler, R., and Coauthors, 2001: The NCEP-NCAR 50-Year Reanalysis: Monthly means CD-ROM and documentation. Bull. Amer. Meteor. Soc., 82, 247-267.

Kushnir, Y. W., A. Robinson, I. Bladé, N. M. J. Hall, S. Peng, and R. Sutton, 2002: Atmospheric GCM response to extratropical SST anomalies: Synthesis and evaluation. J. Climate, 15, 2233-2256.

Kwon, Y.-O., and C. Deser, 2007: North Pacific decadal variability in the Community Climate System Model version 2. J. Climate, in press.

Latif, M., and T. P. Barnett, 1994: Causes of decadal climate variability over the North Pacific and North America. Science, 266, 634-637.

— , and — 1996: Decadal climate variability over the North Pacific and North America: Dynamics and predictability. $J$. Climate, 9, 2407-2423.

Le Traon, P.-Y., and G. Dibarboure, 1999: Mesoscale mapping capabilities of multiple-satellite altimeter missions. J. Atmos. Oceanic. Technol., 16, 1208-1223.

Liu, Z., and L. Wu, 2004: Atmospheric response to North Pacific SST: The role of ocean-atmosphere coupling. J. Climate, 17, 1859-1882.

Mantua, N. J., and S. R. Hare, 2002: The Pacific decadal oscillation. J. Oceanogr., 58, 35-44.

—_ — , Y. Zhang, J. M. Wallace, and R. C. Francis, 1997: A Pacific interdecadal climate oscillation with impacts on salmon production. Bull. Amer. Meteor. Soc., 78, 1069-1079.

Miller, A. J., D. R. Cayan, T. P. Barnett, N. E. Graham, and J. M. Oberhuber, 1994: Interdecadal variability of the Pacific Ocean: Model response to observed heat flux and wind stress anomalies. Climate Dyn., 9, 287-302.

- - , and W. B. White, 1998: A westward-intensified decadal change in the North Pacific thermocline and gyre-scale circulation. J. Climate, 11, 3112-3127.

_, F. Chai, S. Chiba, J. R. Moisan, and D. J. Neilson, 2004: Decadal-scale climate and ecosystem interactions in the North Pacific Ocean. J. Oceanogr., 60, 163-188.

Minobe, S., 1997: A 50-70 year climatic oscillation over the North Pacific and North America. Geophys. Res. Lett., 24, 683-686.

Nakamura, H., and A. S. Kazmin, 2003: Decadal changes in the North Pacific oceanic frontal zones as revealed in ship and satellite observations. J. Geophys. Res., 108, 3078, doi:10.1029/1999JC000085.

_ , G. Lin, and T. Yamagata, 1997: Decadal climate variability in the North Pacific during the recent decades. Bull. Amer. Meteor. Soc., 78, 2215-2225.

Neelin, J. D., and W. Weng, 1999: Analytical prototypes for ocean-atmosphere interaction at midlatitudes. Part I: Coupled feedbacks as a sea surface temperature dependent stochastic process. J. Climate, 12, 697-721.

Niiler, P. P., N. A. Maximenko, and J. C. McWilliams, 2003: Dynamically balanced absolute sea level of the global ocean derived from near-surface velocity observations. Geophys. Res. Lett., 30, 2164, doi:10.1029/2003GL018628.

Nonaka, M., H. Nakamura, Y. Tanimoto, T. Kagimoto, and H. Dasaki, 2006: Decadal variability in the Kuroshio-Oyashio Extension simulated in an eddy-resolving OGCM. J. Climate, 19, 1970-1989. 
Peng, S., W. A. Robinson, and M. P. Hoerling, 1997: The modeled atmospheric response to midlatitude SST anomalies and its dependence on background circulation states. J. Climate, 10, 971-987.

Pierce, D. M., 2001: Distinguishing coupled ocean-atmosphere interactions from background noise in the North Pacific. Prog. Oceanogr., 49, 331-352.

— , T. P. Barnett, N. Schneider, R. Saravanan, D. Dommenget, and M. Latif, 2001: The role of ocean dynamics in producing decadal climate variability in the North Pacific. Climate Dyn., 18, 51-70.

Pierini, S., 2006: A Kuroshio Extension system model study: Decadal chaotic self-sustained oscillations. J. Phys. Oceanogr., 36, 1605-1625.

Qiu, B., 2000: Interannual variability of the Kuroshio Extension and its impact on the wintertime SST field. J. Phys. Oceanogr., 30, 1486-1502.

_ 2003 : Kuroshio Extension variability and forcing of the Pacific decadal oscillations: Responses and potential feedback. J. Phys. Oceanogr., 33, 2465-2482.

_ , and S. Chen, 2005: Variability of the Kuroshio Extension jet, recirculation gyre, and mesoscale eddies on decadal timescales. J. Phys. Oceanogr., 35, 2090-2103.

Saravanan, R., and J. C. Mc Williams, 1998: Advective oceanatmosphere interaction: An analytical stochastic model with implications for decadal variability. J. Climate, 11, 165-188.

Schneider, N., and A. J. Miller, 2001: Predicting western North Pacific Ocean climate. J. Climate, 14, 3997-4002.

- , and B. D. Cornuelle, 2005: The forcing of the Pacific decadal oscillation. J. Climate, 18, 4355-4373.

— A. J. Miller, and D. W. Pierce, 2002: Anatomy of North Pacific decadal variability. J. Climate, 15, 586-605.

Scott, R. B., 2003: Predictability of SST in an idealized, onedimensional, coupled atmosphere-ocean climate model with stochastic forcing and advection. J. Climate, 16, 323-335.

— mate model and its application to the Kuroshio Extension region. J. Climate, 16, 312-322.

Seager, R., Y. Kushnir, N. H. Naik, M. A. Cane, and J. Miller, 2001: Wind-driven shifts in the latitude of the KuroshioOyashio Extension and generation of SST anomalies on decadal timescales. J. Climate, 14, 4249-4265.
Smith, T. M., and R. W. Reynolds, 2004: Improved extended reconstruction of SST (1854-1997). J. Climate, 17, 2466-2477.

Solomon, A., J. P. McCreary Jr., R. Kleeman, and B. A. Klinger, 2003: Interannual and decadal variability in an intermediate coupled model of the Pacific region. J. Climate, 16, 383-405.

Sutton, R., and P. P. Mathieu, 2002: Responses of the atmosphere-ocean mixed layer system to anomalous ocean heat flux convergence. Quart. J. Roy. Meteor. Soc., 128, 1259 1275 .

Taguchi, B., S.-P. Xie, H. Mitsudera, and A. Kubokawa, 2005: Response of the Kuroshio Extension to Rossby waves associated with the 1970 s climate regime shift in a high-resolution ocean model. J. Climate, 18, 2979-2995.

,-- N. Schneider, M. Nonaka, H. Sasaki, and Y. Sasai, 2007: Decadal variability of the Kuroshio Extension: Observations and an eddy-resolving model hindcast. J. Climate, 20, 2357-2377.

Tanimoto, Y., H. Nakamura, T. Kagimoto, and S. Yamane, 2003: An active role of extratropical sea surface temperature anomalies in determining anomalous turbulent heat flux. $J$. Geophys. Res., 108, 3304, doi:10.1029/2002JC001750.

Trenberth, K. E., and J. W. Hurrell, 1994: Decadal atmosphereocean variations in the Pacific. Climate Dyn., 9, 303-319.

Vivier, F., K. A. Kelly, and L. Thompson, 2002: Heat budget in the Kuroshio Extension region: 1993-99. J. Phys. Oceanogr., 32, 3436-3454.

Weng, W., and J. Neelin, 1998: On the role of ocean-atmosphere interaction in midlatitude decadal variability. Geophys. Res. Lett., 25, 167-170.

Wu, L., Z. Liu, R. Jacob, D. Lee, and Y. Zhong, 2003: Pacific decadal variability: The tropical Pacific mode and the North Pacific mode. J. Climate, 16, 1101-1120.

Xie, S. P., T. Kunitani, A. Kubokawa, M. Nonaka, and S. Hosoda, 2000: Interdecadal thermocline variability in the North $\mathrm{Pa}$ cific for 1958-97: A GCM simulation. J. Phys. Oceanogr., 30, 2798-2813.

Yulaeva, E., N. Schneider, D. Pierce, and T. Barnett, 2001: Modeling of North Pacific climate variability forced by oceanic heat flux anomalies. J. Climate, 14, 4027-4046.

Zhang, Y., J. M. Wallace, and D. S. Battisti, 1997: ENSO-like interdecadal variability: 1900-93. J. Climate, 10, 1004-1020. 